\title{
Field Performance of New Methane Detection Technologies: Results from the Alberta Methane Field Challenge
}

Devyani Singh $^{1 *}$, Brenna Barlow ${ }^{2}$, Chris Hugenholtz ${ }^{3}$, Wes Funk ${ }^{2}$, Cooper Robinson ${ }^{4}$, and Arvind P. Ravikumar $^{1,5}$

${ }^{1}$ Center for Environment, Energy, and Economy, Harrisburg University of Science and Technology, Harrisburg, PA 17101

${ }^{2}$ DxD Consulting Inc., Calgary, AB T2P 0S5

${ }^{3}$ Department of Geography, University of Calgary, Calgary, AB T2N 1N4

${ }^{4}$ Radicle Balance, Calgary AB T2P 3CG

${ }^{5}$ Department of Systems Engineering, Harrisburg University of Science and Technology, Harrisburg PA 17101

*Corresponding author email: dsingh5@ harrisburgu.edu

\begin{abstract}
Emerging methane technologies promise rapid and cost-effective methods to measure and monitor methane emissions. Here, we present results from the Alberta Methane Field Challenge - the first large-scale, concurrent field trial of eleven alternative methane emissions detection and quantification technologies at operating oil and gas sites. We evaluate new technologies by comparing their performance with conventional optical gas imaging survey. Overall, technologies are effective at detecting methane emissions, with 8 out of 11 technologies achieving an effectiveness of approximately $80 \%$. Importantly, results highlight the key differences in technology performance between those observed at controlled release tests versus those in field conditions. Intermittent emissions from tanks substantially affects detection and site-level quantification estimates and should be independently monitored while assessing technology performance. In this study, all technologies improved their effectiveness in detecting tank emissions when intermittency was considered. Truck- and plane-based systems have clear advantages in survey speed over other technologies, but their use as effective screening technologies to identify high-emitting sites rests on their quantification effectiveness. Drone-based technologies demonstrated higher effectiveness than other technologies in identifying quantification rank compared to baseline OGI-based survey. Overall, quantification under in-field conditions is affected by several exogenous factors such as temporal variation in emissions and changing environmental conditions. We recommend that assessment studies of new methane detection technologies at oil and gas facilities include comprehensive, continuous, and redundant emissions measurement.
\end{abstract}




\section{Introduction}

Methane emissions across the oil and gas supply chain erode the potential climate benefits of using natural gas over other carbon-intensive fuels such as coal [1]. The Intergovernmental Panel on Climate Change (IPCC) in its recent report on $1.5^{\circ} \mathrm{C}$ of global warming highlighted the importance of reducing short-lived greenhouse gases such as methane [2]. Methane, the major component of natural gas, has a significantly higher global warming potential than carbon dioxide. Recent research has shown that despite their short atmospheric lifetime, methane emissions can contribute to decades of future sea-level rise [3]. Locally, reducing methane emissions also reduces emissions of volatile organic compounds from oil and gas (O\&G) operations and improves air quality [4]. Beyond these local and global impacts, several recent field campaigns to measure methane emissions have demonstrated a consistent underestimation in official GHG inventories [5]-[8]. These discrepancies further underscore the need for effective monitoring and mitigation of $O \& G$ methane emissions. Effective mitigation can also be cost-effective, where 'leaked' methane from fossil fuel operations can be sold to customers or used as on-site fuel [9].

The United States (US), Canada, and Mexico committed to reducing their methane emissions from the O\&G sector as part of the North American Climate, Clean Energy, and Environment Partnership Action Plan [10]. Subsequently, US states such as Colorado and California, and provincial and federal governments in Canada have implemented leak detection and repair (LDAR) programs as part of efforts to reduce emissions from upstream O\&G activities [11][14]. Typically, LDAR surveys are conducted using two commonly used technologies: US Environmental Protection Agency (EPA) Method-21 and optical gas imaging (OGI) systems. While recent studies have found OGI-based LDAR surveys effective in detecting and reducing emissions, they are time-consuming and expensive [10], [15]. OGI-based surveys involve a 2person crew covering $4-6$ well sites per day, which does not scale effectively across thousands of geographically sparse well sites. This makes frequent monitoring challenging even as other studies point to the need to quickly find and repair stochastic, high-emitting leaks [16]-[18]. Recently, several new methane emissions detection technologies that promise faster and more cost-effective leak detection than existing approaches have been developed [19]. These technologies include continuous monitoring systems, mobile sensors mounted on drones, trucks, and planes, handheld sensors, and satellite systems [20]. Most of these technologies are not currently approved for use in regulatory LDAR programs. To enable widespread deployment, the efficacy of new technologies must be validated through rigorous testing, modeling, and field trials.

Recent studies in the US have evaluated a variety of mobile methane detection technologies under controlled conditions [21]-[23]. The Stanford/EDF Mobile Monitoring Challenge, for example, evaluated ten truck-, drone-, and plane-based systems for their effectiveness in detecting and quantifying methane emissions at controlled release test facilities [21]. The US Department of Energy's MONITOR program funded the development of several new methane sensors that were tested under controlled conditions [24]. While these studies provided data on technology parameters such as probability of detection and false positive rates, they are not representative of typical $O \& G$ operations. Thus, systematic field trials at producing $O \& G$ sites are critical to understanding real-world performance of new technologies in detecting and quantifying methane emissions. 
Field studies have been conducted as part of recent methane measurements campaigns. Mobile truck-based platforms were deployed in British Columbia and Alberta to measure site-level emissions, while plane-based systems were used to detect site- and basin-level emissions in the US [25]-[31]. More recently, scientists deployed drone-based systems for methane detection and quantification at O\&G facilities [29], [30], [32]. Finally, satellites have been used to study regional and global methane emissions from anthropogenic and biogenic sources, and to identify high-emitting methane sources associated with O\&G activity [33]-[40]. However, despite the use of alternative technologies in scientific studies for measuring methane emissions from $O \& G$ operations, there has been no systematic field test of their performance.

In this paper, we report results from the Alberta Methane Field Challenge (AMFC) - a largescale, concurrent field trial of alternative methane emissions detection and quantification technologies at operating O\&G sites. We tested twelve different technology teams, including fixed continuous monitoring systems, handheld devices, truck-mounted, drone-mounted, and plane-based systems across 55 upstream O\&G production facilities near Rocky Mountain House, Alberta. The AMFC provides a scientific understanding of the performance of methane emissions detection/quantification technologies under varying field conditions. Critically, our study demonstrates the challenges of evaluating 'snapshot' measurement technologies under spatially and temporally varying methane emissions. We conclude with recommendations on future field testing that can enable a robust performance comparison of new methane detection systems with existing regulatory approaches.

\section{Study Design \& Methodology}

\subsection{Technology Team Selection}

AMFC participants were selected through a rigorous application process that included an application, evaluation of technology platforms, and an invitation to participate (Supplementary Information [SI] Section 1). Participants were selected based on their technological capabilities, prior testing experience, and deployment and scalability. In addition, the number of teams using a specific platform (e.g., drone, truck, plane etc.) were also limited by the logistics of organizing a safe, large-scale, blind, and concurrent field campaign. In all, 40 technologies applied to participate, of which 12 were selected. A summary of the participating technology teams (hereafter referred to as teams) is given in Table 1. The AMFC campaign was held in two phases - phase 1 and 2 - with truck teams participating in both. Detailed technical specification about each participating team is provided in SI section 2. The fixed sensor analysis is included in SI section S3 and not in the main text due to the nature of analysis required as compared to other teams which participated in the AMFC. The Heath team did not report quantified emissions rates or emissions attribution, and the analysis in the SI has been conducted by the authors of this paper. 
81 Table 1: Summary of technology platform, sensor type, and level of detection for each participating team 82 in the $A M F C$.

\begin{tabular}{|c|c|c|c|c|}
\hline Technology Teams & Platform & $\begin{array}{l}\text { AMFC } \\
\text { Phase }\end{array}$ & Sensor Type & $\begin{array}{l}\text { Detection } \\
\text { Resolution }\end{array}$ \\
\hline $\begin{array}{l}\text { Altus Geomatics } \\
\text { (now GeoVerra) }\end{array}$ & Truck & $1 \& 2$ & Cavity ring-down spectroscopy & Site \\
\hline $\begin{array}{l}\text { University of } \\
\text { Calgary (UofC) }\end{array}$ & Truck & $1 \& 2$ & Open-path wavelength modulated spectroscopy & $\begin{array}{l}\text { Equipment \& } \\
\text { Site }\end{array}$ \\
\hline Aerometrix Inc. & Drone & 1 & Tunable open-path laser absorption spectroscopy & Equipment \\
\hline SeekOps Inc. & Drone & 1 & $\begin{array}{l}\text { Miniature methane tunable laser absorption } \\
\text { spectroscopy }\end{array}$ & Equipment \\
\hline Bridger Photonics & Plane & 1 & Spatially scanned airborne LiDAR & $\begin{array}{l}\text { Equipment \& } \\
\text { Site }\end{array}$ \\
\hline $\begin{array}{l}\text { Sander } \\
\text { Geophysics Ltd. }\end{array}$ & Plane & 2 & Off-axis integrated cavity output spectroscopy & Site \\
\hline Tecvalco Ltd. & Hand-held & 2 & Tunable diode laser absorption spectroscopy & Component \\
\hline FLIR Systems & Hand-held & 2 & Uncooled infrared camera & Component \\
\hline $\begin{array}{l}\text { Heath } \\
\text { Consultants Inc. }\end{array}$ & $\begin{array}{l}\text { Hybrid } \\
\text { (truck and } \\
\text { handheld) }\end{array}$ & 1 & $\begin{array}{l}\text { Open-path etalon spectroscopy and backscatter } \\
\text { tunable diode laser absorption spectroscopy }\end{array}$ & $\begin{array}{l}\text { Component } \\
\& \text { Site }\end{array}$ \\
\hline $\begin{array}{l}\text { Heath } \\
\text { Consultants Inc. }\end{array}$ & Fixed & 1 & $\begin{array}{l}\text { Long open-path backscatter tunable diode } \\
\text { laser absorption spectroscopy }\end{array}$ & $\begin{array}{l}\text { Equipment \& } \\
\text { Site }\end{array}$ \\
\hline
\end{tabular}




\subsection{Test Location}

The AMFC phase 1 and phase 2 campaigns were conducted between June 11-21, 2019, and November 14-24, 2019, respectively, across 55 upstream O\&G facilities near Rocky Mountain House, Alberta. These sites were selected based on ease of access, surrounding vegetation type (forested vs. prairie), site-size, and representativeness to assets in the larger production region. Each AMFC phase included measurements at approximately 50 sites, of which 45 overlapped between the two phases. Phase 2 also included a controlled release test set-up to evaluate the quantification accuracy of participating teams. Details on organizing the field campaign, field scheduling, in-field communications, and data integrity and handling procedures can be found in supplementary information - these are provided to assist in the development and execution of future field campaigns (SI section 1).

\subsection{Baseline Data Collection}

Davis Safety Consulting Inc. ('OGI crew') was selected to collect baseline methane emissions data using OGI technology based on prior participation and experience in collecting researchquality data [15]. The OGI crew used a FLIR Technologies' GF-320 infrared camera for emissions detection and the Providence Photonics QL-320 quantitative optical gas imaging (QOGI) instrument for emissions quantification. The QOGI operates by identifying the methane plume pixels on the OGI camera and calculating the effective absorption cross section at each pixel [41]. The baseline data collection included both leaks and vents, and an indication of the temporal nature of the emission (continuous vs. intermittent). The QOGI was selected for emissions quantification over the conventional Bacharach Hi-Flow sampler because of its ability to comprehensively quantify all emissions. The Hi-Flow sampler, on the other hand, can only be used to measure leaks that are accessible and safe and therefore often excludes high emitting sources such as tanks [42]. Furthermore, the maximum flow rate that can be measured with the Hi-Flow sample is 630 standard cubic feet per hour (scfh) [43, p. 8] and large emitters can have significantly higher emission rates [31], [43]-[45]. The quantification accuracy of the QOGI was evaluated through single-blind controlled release measurements (Section 3). Two crews were deployed throughout the AMFC program to increase baseline survey speed. Each day, the OGI crews visited a pre-selected list of 3-5 'mandatory' sites which the participating teams were also required to visit on the same day to minimize temporal mismatch (SI section 1.2). Sites visited by both the participating team and OGI crew on the same day are referred as "overlap sites". In addition, teams could also measure emissions from non-mandatory sites after measurements at mandatory sites were completed.

\subsection{Performance Metrics}

Technologies were assessed on their effectiveness in emissions detection, localization, and quantification as compared to the OGI baseline. In addition, we also analyzed deployment metrics such as survey speed and measurement time relevant in field settings.

Site-level detection effectiveness: The detection effectiveness is defined as the percentage of overlap sites which were identically detected by the participating teams and the baseline OGI survey. This metric only considers site-level binary emissions detection and does not differentiate between the number of sources found within a site for teams that identify equipment-level emissions. Any non-zero emission detected by a team at a given site is given a value of 1 while sites with no detected emissions is given a value of 0 . There are two possible outcomes: one, same detection as OGI which includes scenarios where OGI and the team agree 
on site-level emissions indication (OGI $=1$, team $=1$; and OGI $=0$, team $=0$ ); and two, different detection from OGI which includes scenarios where OGI and the team diverge on site-level emissions indication (OGI $=1$, team $=0$; and $\mathrm{OGI}=0$, team $=1$ ). Mismatch in performance can arise from several factors impacting both OGI and the teams including technology limitations, site configuration, temporal variability in emissions, or weather-related changes to detection thresholds. Moreover, this analysis is distinct from conventional definitions of true positive or true negative measurements employed in controlled release experiments because OGI detections do not necessarily represent the ground truth [21].

Equipment-level detection: For teams that detect equipment-level emissions, effectiveness is defined as the fraction of overlap sites at which a participating team detected emissions across five major equipment categories as compared to the baseline OGI survey: buildings, compressors, wellheads/pumpjacks, separator/dehydrator, and tanks. Equipment descriptions provided by the participating teams that did not fit into any of these categories were grouped under 'other'. As before, this analysis only considers binary emissions detection for each equipment and not individual instances of emissions for a given equipment type. For example, detection of emissions from two or three tanks from the same site are treated equally as an emissions detection from tanks. This simplification is necessary to resolve ambiguities in equipment descriptions as reported by individual teams and OGI. Because major equipment on site can be enclosed in buildings, we consider emissions detection from a building by a team as a proxy for emissions from the equipment inside the building as identified by OGI. This assumption was also applied to separator/dehydrator and compressors that are often enclosed in buildings.

Site-level Emissions Quantification Accuracy: Quantification accuracy is shown as a parity chart of rank-ordered emissions by OGI and the participating teams at overlap sites. Here, accuracy is defined as the number of overlap sites ranked within $20 \%$ of OGI ranks. This metric has been aggregated at the site-level for teams that measure equipment-level emissions. Consequently, site-level aggregation of participating teams may not include all the emissions identified at the site by the OGI team. In this case, differences in quantification can arise from errors in quantification, 'missed' equipment-level detections, or temporal variation in emissions. Parity charts of site-level quantification accuracy between teams and baseline OGI survey are provided in SI section 6.

\section{Quantification Accuracy of QOGI}

Here, we report on results from the controlled release test of the Providence Photonics' QL-320 quantitative optical gas imaging (QOGI) instrument during the AMFC phase 2 campaign. The controlled release tests were conducted on a non-operating $\mathrm{O} \& \mathrm{G}$ site that was verified to not have any residual methane emissions but was still subject to similar environmental conditions as operating sites. The releases were roughly equally split between two release heights $-5 \mathrm{ft}$ and 15 $\mathrm{ft}$ (SI section 4.1). Across the 11 days of the AMFC phase- 2 campaign, each of the two OGI crews took part in approximately 50 controlled releases ranging from about $30 \mathrm{scfh}$ to $1900 \mathrm{scfh}$. The emissions rates were chosen not to evaluate the detection threshold for the OGI camera but to test quantification accuracy of QOGI across the range of emissions typically observed at O\&G 
facilities. For more details on experimental set-up and uncertainty analysis of the QOGI performance, refer to SI section 4.

Figure 1 (a) shows the parity chart of controlled release tests for the QOGI across both measurement heights and OGI crews. A least-squares linear regression coefficient of 0.82 was observed $\left(\mathrm{R}^{2}=0.6,95 \%\right.$ confidence interval $\left.[0.73,0.92]\right)$, thus demonstrating reasonable effectiveness in estimating aggregate emissions rates. For tests below $1000 \mathrm{scfh}$, the slope of linear regression is 0.86 , with a $95 \%$ confidence interval between 0.72 and 1 . The aggregate error in quantification from controlled release tests is $18 \%$ across the range of release rates, comparable to that of the Bacharach Hi-Flow sampler $(\sim 10 \%)$ [43]. This aggregate error rate will change depending on the number of emissions per site, where it will be larger for sites with fewer emissions. Figure 1 (b) shows the parity chart of emission rank for the true release rates and the QOGI estimated rates, ranked largest to smallest. The QOGI instrument was 72\% effective in estimating emission rank within $20 \%$ of the rank of the true release rates.
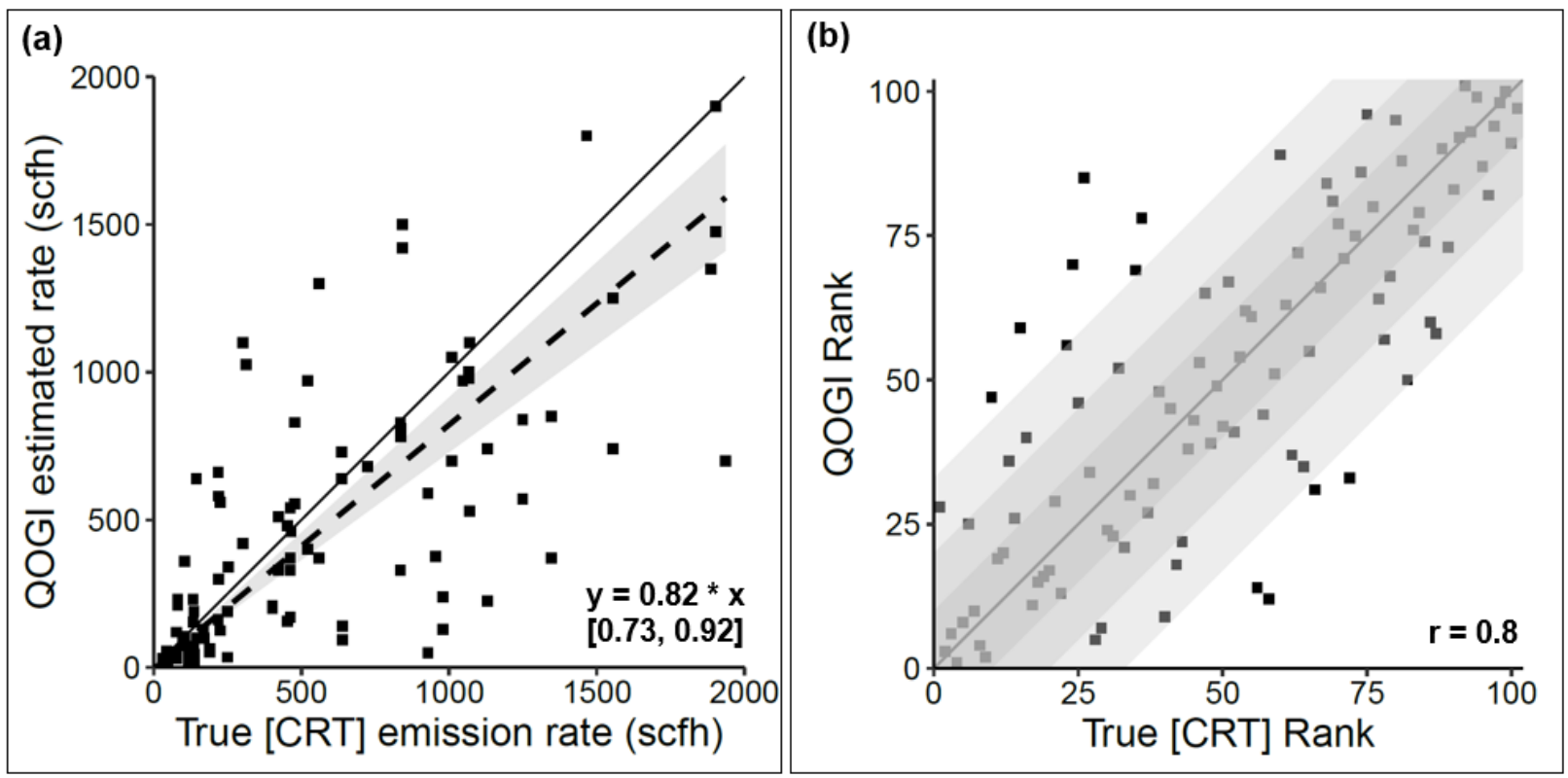

Figure 1: (a) Parity chart of controlled release tests for QOGI across both measurement heights (5 feet and 15 feet) and the two OGI crews. (b) Parity chart of quantification rank between OGI and true CRT rank. The largest emission is given a rank of 1. The black reference line shows a 1:1 relationship where OGI rank $=$ CRT rank and has a slope $=1$. The gray shaded region shows OGI ranked emissions within $10 \%$ (darkest), 20\%, and 33\% (lightest) of CRT ranks.

To further improve our understanding of measurement uncertainty in QOGI-based quantification estimates, we use Monte-Carlo analysis to estimate error as a function of sample size (SI section 4.1). Using a bootstrapped sampling technique (with replacement) and 10,000 Monte-Carlo realizations, we find that the $5^{\text {th }}$ and $95^{\text {th }}$ percentile of the sample mean are $-23 \%$ and $+26 \%$, respectively, for a sample size of 50 (SI Figure S7). Similarly, at a sample size of 20 emissions typically seen in production sites - the $95 \%$ confidence bounds of the average emission rate is - 
$34 \%$ and $+39 \%$. Thus, it is critical for QOGI measurements to be interpreted in an aggregate context, as individual measurements can have higher error rates as shown in Figure 1(a). Nevertheless, the critical advantage of being able to estimate all methane emissions at a site outweighs the higher error in QOGI-based quantification. Detailed analysis showing the variation of quantification effectiveness with release height (SI Figure S4) and thermographer operation (SI Figure S5) are available in the SI. Even as this study provides the first large-scale, independent verification of the quantification accuracy of the QOGI instrument, future work is critical to improve our understanding of the precision of the instrument under realistic equipment configurations - different orifice sizes, backgrounds, weather conditions, and gas compositions.

\section{Results}

In this section we present results from both phases of the AMFC. A few caveats will help in interpreting results.

1. Many of the participating teams are early-stage technology companies (technology readiness levels $4-7$ ) and the results reported here are likely not representative of their most up-to-date performance.

2. Because of the inherent uncertainty in detecting methane emissions at operating $O \& G$ facilities, the results reported here do not represent the ground truth performance of participating teams but rather a relative comparison with OGI-based leak detection surveys. Determining technology-specific parameters such as leak detection threshold will require detailed controlled release experiments similar to the Mobile Monitoring Challenge [21].

3. Several prior studies emphasize the importance of temporal variation in methane emissions [5], [7], [31], [46]-[48]. Differences in performance between teams and baseline OGI data likely arise from a combination of technology performance limitations, intra-day changes in methane emissions, variation in environmental conditions, or other factors such as downwind access to emitting equipment.

\subsection{Site-level Emissions Detection}

Table 2 shows a summary of the site-level performance of the participating teams. The comparison with baseline OGI survey is only made at overlap sites, which is limited by the survey speed of the OGI team (3-6 sites/day). We make several important observations.

First, seven out of eleven teams demonstrate high effectiveness (approximately 80\%) in detecting site-level methane emissions compared to the baseline OGI survey. Laser-based technologies tend to have higher sensitivity compared to imaging-based sensors such as OGI cameras and therefore emissions that are detected by OGI tend to also be detected by other laserbased technologies. In particular, SeekOps (drone), Aerometrix (drone), and Heath (hybrid), found emissions at a site where OGI did not. These emissions were found on tanks that were either likely not in the line-of-sight for a ground based OGI crew, or they could be intermittent in nature and thus not emitting when OGI was on site. The low detection effectiveness of FLIR Systems can be attributed to the lower sensitivity of uncooled infrared imaging systems compared to the baseline OGI survey that used cooled infrared detectors. The detection effectiveness of plane-based systems varied based on the metric chosen. In the case of Bridger Photonics, only 'tier-1' emissions - where the technology was able to localize and quantify methane plumes were considered, leading to a $43 \%$ detection effectiveness. In addition, Bridger 
also identified 'tier-3' emissions that correspond to plumes that were observed but too weak to localize or quantify. Including these 'tier-3' emissions, the detection effectiveness increased to 90\%. However, 'tier-3' emissions detections cannot be used for follow-up emissions mitigation action as the weak plumes could not be localized. Similarly, although Sander Geophysics' detected emissions at $77 \%$ sites found by the OGI crew, they were only able to quantify emissions from four sites because of unstable wind conditions.

Second, survey speed varied from 3 sites/day for Tecvalco to 15 sites/day for Altus Geomatics, indicative of the range of survey methods employed. On average, aerial and truck-based systems that measure at the site-level are at least three to five times faster than the baseline OGI survey. For all technologies, survey speeds as part of an LDAR program deployment can be expected to be somewhat higher than those observed in this study because of artificial constraints that restricted survey speed. For example, not all sites in the region were measured in the AMFC campaign and so a greater fraction of time was spent traveling between sites. Furthermore, the need to wait for a prior team to finish measurements if teams ended up on a site concurrently further reduced survey speed. The aerial teams (drones and planes) flew only for $2-4$ hours per day and thus their survey speed is lower than what should be expected if they flew more hours per day. The lower average survey speed for truck-based systems in the phase 2 campaign compared to the phase 1 campaign can be attributed to the addition of controlled release testing, winter driving conditions, and shorter daylight hours in November.

Third, measurement time varied between under 10 minutes per site for Bridger, UofC, and Altus to over 30 minutes per site for other teams. For comparison, the baseline OGI survey took an average of 76 minutes per site, as per the design of the field campaign. The average measurement time for handheld teams is between 30 and 60 minutes per site, with the variation depending on quantification protocols for the team. However, handheld and hybrid (Heath) teams provided actionable information for component-specific repair, unlike other equipment- or site-level technologies, and should be considered in context of their application. In general, truck- and plane-based teams were faster than the baseline OGI survey. Both truck teams had similar survey times but varied in survey speed. These differences can be partly attributed to differing survey methodologies and additional time to collect ancillary data such as site layout by the UofC team, or partly may arise because Altus is commercial service provider and UofC is a research institution. Differences in time spent on site between Bridger ( $7 \mathrm{~min} / \mathrm{site}$ ) and Sander (23 $\mathrm{min} / \mathrm{site}$ ) can be attributed to Sander surveying sites by flying loop patterns around each site compared to Bridger conducting two to four passes over the site. This difference in survey methodology, in turn, may be a function of the sensor technologies deployed - Bridger's technology is based on hyperspectral imaging while Sanders' is based on direct measurements of methane concentration. Measurement time notwithstanding, all teams that measured emissions at the equipment- or site-level will require secondary inspection for repair. The time required for secondary, component-level inspection is not included in this analysis. 
Table 2: Site-level performance for participating teams in the Alberta Methane Field Challenge (AMFC) as compared to baseline OGI survey.

\begin{tabular}{|c|c|c|c|c|c|c|c|c|c|c|c|c|}
\hline \multirow[b]{2}{*}{ Tech. Team } & \multirow[b]{2}{*}{ Type } & \multirow{2}{*}{$\begin{array}{l}\text { AMFC } \\
\text { Phase }\end{array}$} & \multirow{2}{*}{$\begin{array}{c}\text { No. } \\
\text { of } \\
\text { days }\end{array}$} & \multirow{2}{*}{$\begin{array}{c}\text { Total } \\
\text { sites } \\
\text { visited }\end{array}$} & \multirow{2}{*}{$\begin{array}{l}\text { Overlap } \\
\text { sites }\end{array}$} & \multirow{2}{*}{$\begin{array}{c}\text { Survey } \\
\text { speed } \\
\text { (sites } \\
\text { /day) } \\
\end{array}$} & \multirow{2}{*}{$\begin{array}{l}\text { Survey } \\
\text { time } \\
\text { (min } \\
\text { /site) } \\
\end{array}$} & \multirow{2}{*}{$\begin{array}{c}\text { Effective- } \\
\text { ness } \\
(\%)\end{array}$} & \multicolumn{2}{|c|}{ Same as OGI } & \multicolumn{2}{|c|}{ Diff. from OGI } \\
\hline & & & & & & & & & $\begin{array}{l}\text { OGI=1, } \\
\text { Team }=1\end{array}$ & $\begin{array}{l}\text { OGI }=0, \\
\text { Team }=0\end{array}$ & $\begin{array}{l}\text { OGI }=0, \\
\text { Team }=1\end{array}$ & $\begin{array}{l}\text { OGI }=1, \\
\text { Team }=0\end{array}$ \\
\hline Aerometrix Inc. & Drone & 1 & 10 & 42 & 29 & 5 & 20 & $79 \%$ & 23 & 0 & 2 & 4 \\
\hline SeekOps Inc. & Drone & 1 & 11 & 54 & 38 & 5 & 36 & $92 \%$ & 35 & 0 & 1 & 2 \\
\hline Bridger Photonics* & Plane & 1 & 5 & 65 & 20 & $13^{\dagger}$ & 7 & $40 \%$ & 6 & 2 & 0 & 12 \\
\hline $\begin{array}{l}\text { Sander } \\
\text { Geophysics** }\end{array}$ & Plane & 2 & 7 & 39 & 30 & $6^{\dagger}$ & 23 & $77 \%$ & 23 & 0 & 1 & 6 \\
\hline Tecvalco Itd. & Hand. & 2 & 5 & 10 & 9 & 3 & 52 & $89 \%$ & 8 & 0 & 0 & 1 \\
\hline FLIR Systems & Hand. & 2 & 5 & 26 & 24 & 5 & 36 & $29 \%$ & 5 & 2 & 0 & 17 \\
\hline Heath Consultants & Hybrid & 1 & 11 & 53 & 45 & 5 & 41 & $91 \%$ & 41 & 0 & 4 & 0 \\
\hline $\begin{array}{l}\text { Altus Geomatics } \\
\text { (now GeoVerra) }\end{array}$ & Truck & 1 & 10 & 127 & 40 & 15 & 9 & $88 \%$ & 33 & 2 & 0 & 5 \\
\hline $\begin{array}{l}\text { Altus Geomatics } \\
\text { (now GeoVerra) }\end{array}$ & Truck & 2 & 11 & 90 & 47 & 8 & 5 & $94 \%$ & 43 & 1 & 1 & 2 \\
\hline $\begin{array}{l}\text { Univ. of Calgary } \\
\text { (UofC) }\end{array}$ & Truck & 1 & 11 & 90 & 47 & 8 & 10 & $81 \%$ & 36 & 2 & 2 & 7 \\
\hline $\begin{array}{l}\text { Univ. of Calgary } \\
\text { (UofC) }\end{array}$ & Truck & 2 & 11 & 54 & 41 & 5 & 6 & $90 \%$ & 36 & 1 & 1 & 3 \\
\hline
\end{tabular}

* Only 'tier-1' emissions where the technology was able to localize and quantify methane plumes were considered. Bridger Photonics also identified 'tier-3' emissions that correspond to plumes that were observed but too weak to localize or quantify. Including these 'tier-3' emissions, the detection effectiveness increases to $90 \%$. However, 'tier-3' emissions detections cannot be used for follow-up emissions mitigation action as the weak plumes could not be localized.

** Sander only reported and quantified 4 emissions of which 2 overlap with OGI which leads to an effectiveness of 16\%. The 77\% effectiveness is based on all detections made by Sander Geophysics irrespective of their ability to quantify those detections. Sites where emissions could not be resolved from other sources have not been included, similar to Bridger's 'tier 3' emissions.

$\dagger \quad$ Plane technologies only flew $2-4$ hours day, resulting in a lower survey speed than can be expected in a typically 8-hour measurement campaign. 
Based on comparisons with site-level baseline OGI survey emissions quantification, we find that most teams show a clear differentiation between sites where both OGI and the team found emission and sites where only OGI found emissions. Figure 2 shows the average site-level emissions quantification estimated by the baseline OGI survey at overlap sites, comparing identically detected sites $(\mathrm{OGI}=1$, Team $=1$ ) with where a divergence between OGI and the team was observed (OGI=1, Team=0). It is important to not interpret these differences as indicative of detection thresholds of the technologies, which are evaluated through controlled releases tests. The data here highlight important differences in technology performance between those observed at controlled release tests versus those at producing $O \& G$ facilities.

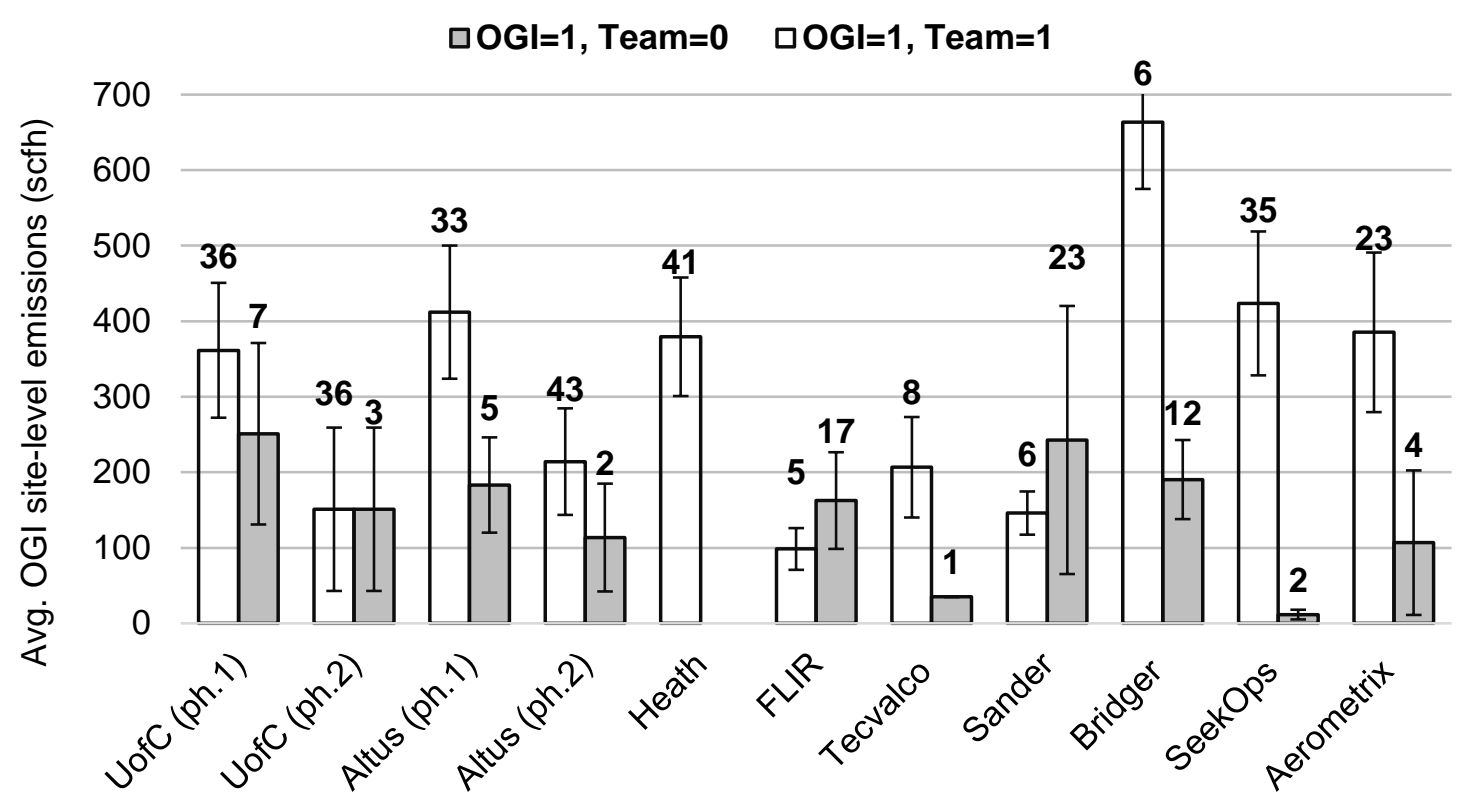

Figure 2: Average site-level emissions (scfh) estimated by QOGI at overlap sites where teams and OGI both detected emissions (black outline), and where teams failed to detect but OGI made a detection (grey bars). Error bars represent one standard error from the mean. Numbers represent sample size for emissions calculation.

For most participating teams, the average baseline OGI site-level emissions rates were higher at sites where the teams' also detected emissions compared to sites where the teams did not detect emissions. For example, the average site-level emission estimated by QOGI at sites that SeekOps also detected is $420 \mathrm{scfh}$, while the average emissions at sites where SeekOps did not detect emissions found by the OGI crew is $20 \mathrm{scfh}$. However, UofC (both phases) and Altus (phase 2) do not show a significant divergence in average emissions rates between similar and different OGI detections. Although this data does not represent detection thresholds as typically determined through controlled release tests, it provides an indication of the real-world detection capabilities where new technologies have to isolate leaks from complex ambient conditions exhibiting spatial and temporal variations in methane.

\subsection{Equipment-level Emissions Detection}

Table 3 shows the detection effectiveness across five major equipment types at overlap sites for teams that detected equipment level emissions. We make several observations. 
312

313

314

315

316

317

318

319

320

321

322

323

324

325

326

327

328

329

330

331

332

333

334

335

336

337

338

339

340

341

342

343

344

345

346

347
First, the drone and truck teams designed to detect equipment-level emissions (SeekOps, Aerometrix, UofC, Heath) demonstrated effectiveness over $65 \%$ in detecting the correct emitting equipment category compared to baseline OGI survey. While SeekOps was $81 \%$ effective, Aerometrix had an overall effectiveness of $70 \%$. However, Aerometrix reported several emitting equipment sources as plausible source locations for each emission, thus, significantly reducing the localization effectiveness for future repairs.

Second, teams exhibit significant variation in detection effectiveness across equipment types. Both the drone teams demonstrated over $67 \%$ effectiveness in detecting tank emissions. In comparison, the UofC truck-based team demonstrated $32 \%$ and 55\% effectiveness in identifying tank-related emission in the two phases of the AMFC campaign. However, across all equipment categories, the UofC team detected at least $67 \%$ of emissions identified by the baseline OGI survey. The low effectiveness for truck systems in detecting tank emissions could be a result of unstable atmospheric conditions that leads to plume lofting or limitations to downwind access to major equipment. This difference between tanks and other equipment types suggests further testing for truck-based teams to identify potential issues with sampling emissions at height such as tanks and flare stacks. Moreover, when we exclude intermittent tank emissions as noted by the baseline OGI survey, the effectiveness in detecting emissions from tanks increases for all teams - Aerometrix (72\%), SeekOps (92\%) Heath (69\%), UofC phase 1 (50\%), UofC phase 2 $(65 \%)$, and Tecvalco (60\%). Thus, intermittency of tank emissions is a critical factor in determining the effectiveness of new technologies that provide snapshot methane measurements.

Third, Bridger Photonics, a plane-based technology, had lower effectiveness in equipment-level detections $(56 \%)$ compared to other technologies - however, small sample size of 'tier-1' emissions ( 7 sites) prevent any statistical inference. It was $25 \%$ effective in detecting tanks and $67 \%$ effective in detecting buildings and separators/dehydrators. The separator and dehydrators detected here are not the ones reported by Bridger, but those where OGI specified that the equipment was in a building, and Bridger successfully identified an emission from a building. Compressors, separators, dehydrators, and other equipment in cold regions are often enclosed in buildings, making it difficult for a plane-based team to identify the emitting equipment.

Finally, both hand-held teams had a lower overall effectiveness at detecting equipment-level emissions compared to other teams. Tecvalco's effectiveness ranged from 30-50\% across equipment types for the 10 reported sites. The low number of detections is likely because Tecvalco reported only quantifiable emissions from sources that were safely accessible to attach a flowmeter. FLIR reported emissions only from buildings and wellheads, resulting in a relatively low effectiveness of $26 \%$ and $13 \%$, respectively. Furthermore, the uncooled FLIR GF77 infrared camera used by the FLIR team has a significantly lower sensitivity compared to the cooled infrared camera used in the baseline OGI-survey. 
Table 3: Equipment-level performance showing site-level detection effectiveness (\%) for each team in bold across five major equipment types tanks, wellhead/pumpjack, compressor, separator/dehydrator, and buildings. Overall (\%) is the average effectiveness for the team across all equipment types. Data are only for those sites where the equipment was identified by QOGI. Blanks are for those teams which did not report equipment of that kind at all. If QOGI or a team identified a building, while the other identified a compressor or separator/dehydrator it has been marked under both as this equipment in cold regions are often enclosed in buildings, making it difficult for teams to identify the emitting equipment if they are unable to gain access. When adjusted for intermittent tank emissions as identified by OGI - Aerometrix (72\%), SeekOps (92\%), Heath (69\%), UofC phase 1 (50\%), UofC phase 2 (65\%), Tecvalco (60\%).

\begin{tabular}{|c|c|c|c|c|c|c|c|c|c|c|c|c|c|c|c|c|}
\hline \multirow{3}{*}{ Technology teams } & \multirow{3}{*}{$\begin{array}{c}\text { Overall } \\
(\%)\end{array}$} & \multicolumn{3}{|c|}{ Tanks } & \multicolumn{3}{|c|}{$\begin{array}{l}\text { Wellhead / } \\
\text { PumpJack }\end{array}$} & \multicolumn{3}{|c|}{ Compressor } & \multicolumn{3}{|c|}{$\begin{array}{l}\text { Separator / } \\
\text { Dehydrator }\end{array}$} & \multicolumn{3}{|c|}{ Buildings } \\
\hline & & \multicolumn{2}{|c|}{ Team } & \multirow{2}{*}{$\begin{array}{c}\text { OGI } \\
\#\end{array}$} & \multicolumn{2}{|c|}{ Team } & \multirow{2}{*}{$\begin{array}{c}\text { OGI } \\
\#\end{array}$} & \multicolumn{2}{|c|}{ Team } & \multirow{2}{*}{$\begin{array}{c}\text { OGI } \\
\#\end{array}$} & \multicolumn{2}{|c|}{ Team } & \multirow{2}{*}{$\begin{array}{c}\text { OGI } \\
\#\end{array}$} & \multicolumn{2}{|c|}{ Team } & \multirow{2}{*}{$\begin{array}{c}\text { OGI } \\
\frac{\#}{}\end{array}$} \\
\hline & & $\%$ & $\#$ & & $\%$ & $\#$ & & $\%$ & $\#$ & & $\%$ & $\#$ & & $\%$ & $\#$ & \\
\hline Aerometrix & $70 \%$ & 67 & 12 & 18 & 73 & 8 & 11 & 40 & 2 & 5 & 75 & 15 & 20 & 73 & 16 & 22 \\
\hline SeekOps & $81 \%$ & 88 & 22 & 25 & 70 & 14 & 20 & 67 & 4 & 6 & 85 & 22 & 26 & 83 & 24 & 29 \\
\hline Heath (Hybrid) & $76 \%$ & 58 & 15 & 26 & 63 & 15 & 24 & 75 & 6 & 8 & 90 & 28 & 31 & 88 & 30 & 34 \\
\hline Bridger & $56 \%$ & 25 & 1 & 4 & & & & & & & 67 & 4 & 6 & 67 & 4 & 6 \\
\hline UofC (phase 1) & $67 \%$ & 32 & 9 & 28 & 64 & 16 & 25 & 75 & 6 & 8 & 82 & 27 & 33 & 81 & 29 & 36 \\
\hline UofC (phase 2) & $75 \%$ & 55 & 11 & 20 & 43 & 6 & 14 & 50 & 4 & 8 & 90 & 28 & 31 & 91 & 30 & 33 \\
\hline Tecvalco & $34 \%$ & 40 & 2 & 5 & 50 & 2 & 4 & & & & 30 & 3 & 10 & 30 & 3 & 10 \\
\hline FLIR & $30 \%$ & & & & 13 & 1 & 8 & & & & & & & 26 & 5 & 19 \\
\hline
\end{tabular}




\subsection{Site-level Emissions Quantification}

\subsubsection{Flow Rate Quantification}

Figure 3 shows the scatter and box plots for site-level emissions quantification at overlap sites for each participating team in AMFC phase 1 and phase 2 campaigns. The sites are shown in descending order of average emissions measured by all teams and the baseline OGI crew. To compare observations across teams, we aggregated all component-level and equipment-level measurements to the site-level. While we analyze quantification performance in comparison to baseline OGI measurements, most jurisdictions with LDAR regulations do not currently require any emissions quantification.

The average site-level emission rate for all sites measured by baseline OGI in phase 1 was $359 \pm$ $146 \mathrm{scfh}$ with median $146 \mathrm{scfh}$, and in phase 2 was $213 \pm 128 \mathrm{scfh}$ with median $91 \mathrm{scfh}$, respectively. There is wide variation in quantification effectiveness across teams - parity chart of site-level quantification accuracy between teams and baseline OGI for overlap sites show regression coefficients between 0.08 and 0.83 - see SI section 6 for more details.

Site-level emissions quantification varied by over an order of magnitude across all participating teams. The drone-based teams reported average emission rates lower than that of OGI Aerometrix under-estimated on average by $87 \%$ (median $16 \mathrm{scfh}$, mean $53 \pm 37 \mathrm{scfh}$ ), and Seekops underestimated flow rates on average by $62 \%$ (median $21.3 \mathrm{scfh}$, mean $134 \pm 100 \mathrm{scfh}$ ). For the plane teams, Sander estimated an average twice that of OGI (920 scfh) for two overlap sites, and Bridger underestimated by $75 \%$ (median $184 \mathrm{scfh}$, mean $153 \pm 113 \mathrm{scfh}$ ) for the seven overlap quantified sites. However, these cannot be assumed to be statistically representative because of the small sample size of sites with quantified emission rates.

Both truck teams had better quantification accuracy in phase 2 as compared to phase 1: average underestimation as compared to baseline OGI for Altus was $92 \%$ in phase 1 and $76 \%$ in phase 2 while that for UofC was 58\% in phase 1 and $17 \%$ in phase 2. Altus, which measured site-level emissions, estimated an order of magnitude lower emission rate compared to OGI in both phases. In phase 1, Altus estimated a median emission rate of $3.5 \mathrm{scfh}$ (mean $32 \pm 33 \mathrm{scfh}$ ), compared to baseline OGI median emission rate at overlap sites of $161 \mathrm{scfh}$ (mean $353 \pm 162 \mathrm{scfh}$ ). In phase 2, Altus estimated a median emission rate of $17 \mathrm{scfh}$ (mean $51 \pm 24 \mathrm{scfh}$ ), compared to baseline OGI median emission rate at overlap sites of $88 \mathrm{scfh}$ (mean $137 \pm 42 \mathrm{scfh}$ ). The UofC average emission rate across all sites were within $25 \%$ of OGI in phase 1 (median $292 \mathrm{scfh}$, mean $402 \pm$ $113 \mathrm{scfh}$ compared to OGI mean $312 \pm 146 \mathrm{scfh}$ ) but twice that of OGI in phase 2 (median 210 scfh, mean $296 \pm 99 \mathrm{scfh}$ compared to OGI mean $144 \pm 65 \mathrm{scfh}$ ).

Tecvalco, the handheld team that quantified component-level emissions, reported a mean emission rate of $92 \pm 178 \mathrm{scfh}$ and a median of $14 \mathrm{scfh}$, that is half that of OGI mean $188 \pm 142$ scfh. However, Tecvalco's site-level quantification does not include all emissions detected by the team at any given site as quantification was only performed for emitting sources that were accessible and safe. Thus, the underestimation of site-level emissions in comparison to baseline OGI survey is expected. 


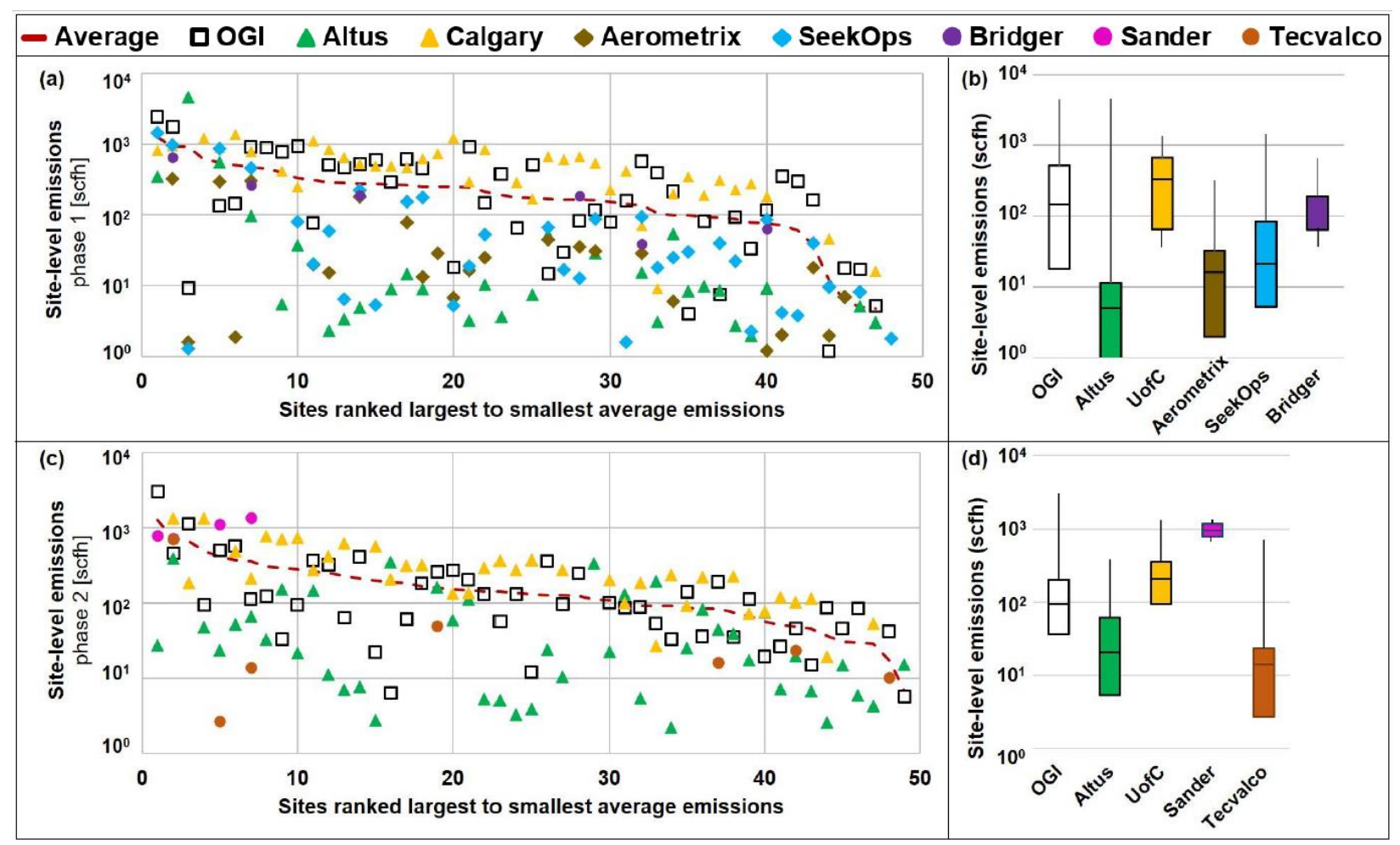

395

Figure 3: Scatter plot on log scale (y-axis) showing site-level emissions quantification by the participating teams - Altus Geomatics (green triangles), University of Calgary (Yellow triangles), Aerometrix (brown diamonds), SeekOps (blue diamonds), Bridger Photonics (purple circles), Sander Geophysics (pink circles), Tecvalco (brown circles) - and OGI (black squares) at overlap sites in standard cubic feet per hour (scfh) in (a) Phase 1, and (c) Phase 2 of the AMFC program. Sites are ranked from largest average emitting site across all technologies to smallest average emitting site, shown as a red dotted line. ( $b$ and d) Box plots show the $25^{\text {th }}$ and $75^{\text {th }}$ quartile range with median site-level emissions, while the error bars (whiskers) show the $10^{\text {th }}$ and $90^{\text {th }}$ percentile.

The underestimation observed between OGI and the teams can arise from several factors. First, not all leaks can be quantified because of accessibility or safety constraints. Second, instantaneous changes to wind directions may prevent an accurate estimation of emission rate, particularly if the technology relies on Gaussian plume dispersion assumptions. Third, potential on-site intra-day variation in emissions may lead to teams measuring vastly different emission rates - this is especially relevant for tank flashing events. Fourth, effectiveness of algorithms that convert raw measurement data to emission flow rates and the design of the sensors may prevent effective measurement of some types of emissions (point source vs. diffused). The critical insight here is that differences in observed emission rates points to the difficulty in effective quantification under field conditions. Efforts to attribute differences in quantification estimates require detailed controlled release experiments that individually test for the impact of confounding variables such as wind direction, wind stability, nature of emission, and emission rate. Furthermore, such field trials of new technologies might require obtaining baseline quantification through multiple, independent methods in the field such as fixed tower sites, tracers, and other established methods to improve redundancy and observe the role of intermittent emissions. 


\subsubsection{Quantification Rank Parity}

Quantification, in general, is a challenging problem [5], [7], [31], [46]. Some technologies propose site-level quantification to triage and direct follow-up close-range inspection for possible repairs. For those reliant on quantification-based triaging, accuracy in ranking the highest and lowest emitting sites is paramount. Figure 4 shows a quantification rank parity chart between teams and OGI, with the highest emitting site as identified by the baseline OGI survey ranked 1. The different shaded regions correspond to sites where the teams ranked within $10 \%$, $20 \%$, and $33 \%$ of OGI ranks in either direction. In this analysis, we define accuracy as the number of overlap sites ranked within $20 \%$ of OGI ranks.
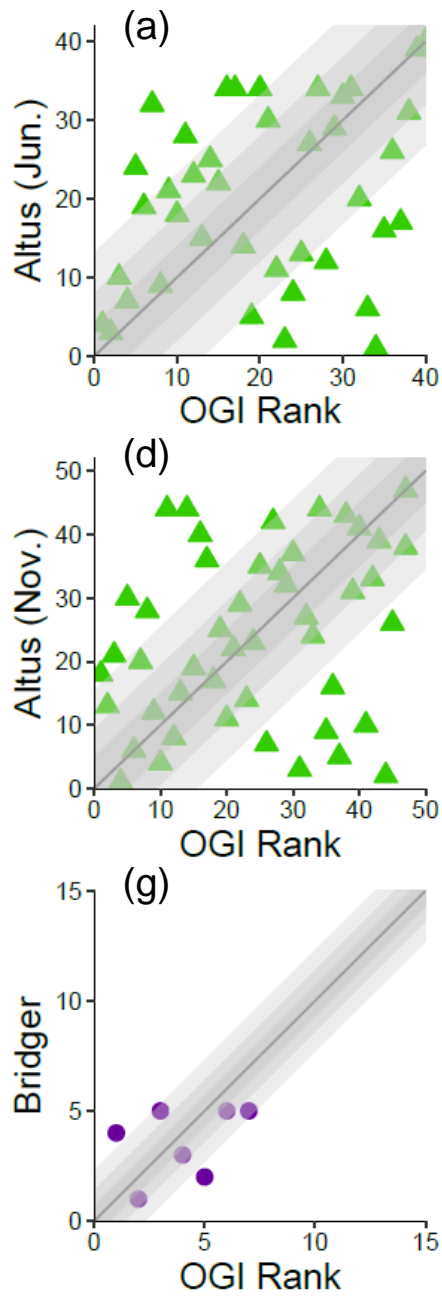
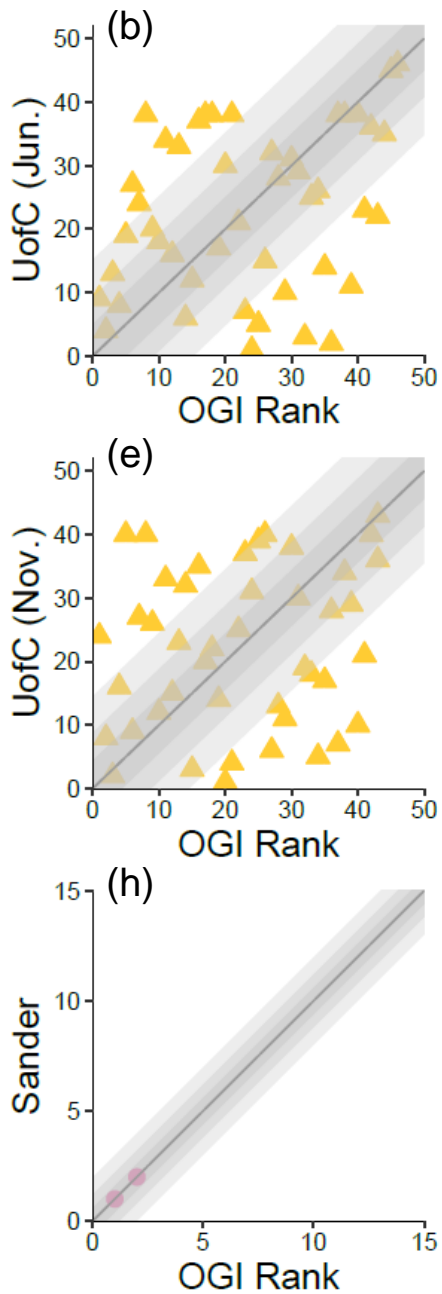
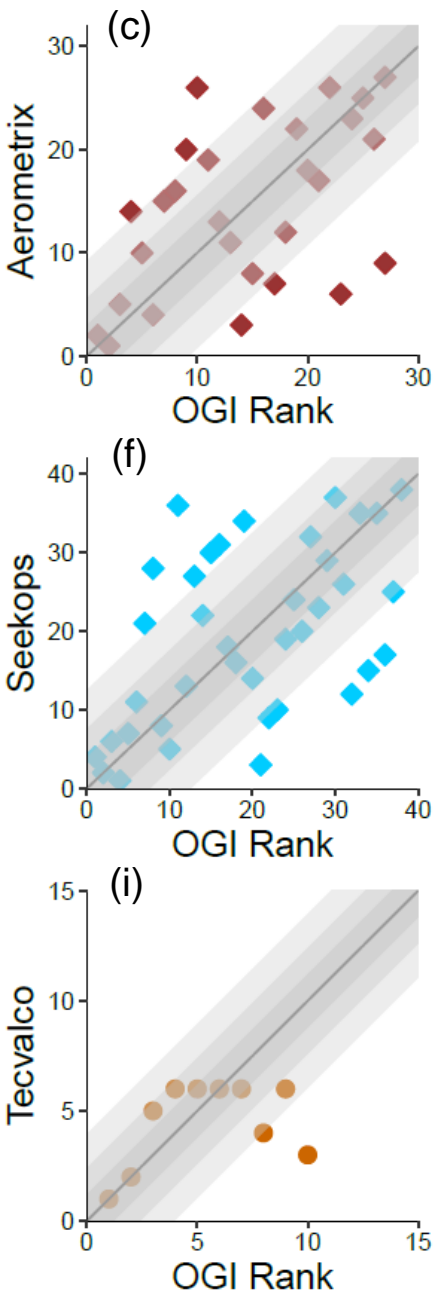

Figure 4: Parity chart of quantification rank between OGI and participating teams. The largest emitting site is given a rank of 1. The two truck teams (UofC and Altus) participated in both June and November campaigns. The black reference line shows a 1:1 relationship where OGI rank $=$ team rank and has a slope $=1$. The gray shaded region shows where team ranked sites within 10\%, 20\%, and 33\% of OGI ranks (darkest gray $=10 \%$, lightest gray $=33 \%)$. Only teams that quantified emissions are shown in this figure.

Drone- and plane-based teams are reasonably effective at estimating the rank-order of site-level methane emissions. Aerometrix and SeekOps demonstrated an accuracy of 57\% and 63\%, respectively. While the overall correlation between the drone teams and OGI ranking is only 
moderate (Pearson's correlation coefficient ' $r$ ' $=0.5$ ), both teams correctly identified $60 \%$ of the top 10 highest and lowest emitting sites in comparison to OGI. Bridger was accurate for three of the seven quantified overlap sites. However, this effectiveness could change as the two plane teams have a relatively small sample size: Bridger with 7 and Sander with 2 sites.

The truck-based teams were between 39-55\% accurate across both phase 1 and phase 2 campaigns with a relatively low correlation between their ranks and OGI ranks: Altus with $\mathrm{r}=$ 0.3 and $r=0.28$ for phase 1 and 2 respectively, and UofC with $r=0.3$ and $r=0.17$ for phase 1 and 2, respectively. Tecvalco reported quantification data for component-level sources from 10 sites that were accessible and safe to measure. Of these, Tecvalco was within $20 \%$ of OGI ranks for 7 sites, where it identically ranked the top two emitting sites similar to OGI.

\section{Discussion}

The Alberta Methane Field Challenge (AMFC) was the first large-scale, concurrent field trial of alternative methane emissions detection and quantification technologies at operating O\&G sites. We compared team performance for 12 fixed, hand-held, truck-, drone-, and plane- based technologies to conventional OGI surveys. Most technologies tested were effective at detecting site-level methane emissions but demonstrated varying effectiveness in localization, survey speed, and quantification. While this field test is by no means a comprehensive analysis of field performance, the study reveals several insights that would be critical for future scientific research as well as public policy on methane emissions.

First, the hand-held teams showed no significant technological advantage over OGI in detection or quantification performance. While the FLIR team (uncooled IR camera) was faster at site surveys compared to OGI and Tecvalco, it had low detection effectiveness and did not quantify emissions. Alternately, while Tecvalco was highly effective in emissions detection, quantification was limited to safe and accessible sources. In practice, this often excludes high emitting sources such as tanks.

Second, there are distinct advantages of plane- and truck-based teams in survey speed over other technologies tested (drones, and hand-held). However, they will all require some level of secondary close-range inspection to find and repair emitting components. Thus, the effectiveness of technologies that rely on quantification to direct follow-up component-level source identification and repairs risk identifying sites with any methane emission above the detection threshold for potential follow-up. On the other hand, drone-based systems can be effective in detecting emissions that pose access challenges to other ground-based crews. However, they may not provide any significant advantages in terms of survey speed compared to OGI and other hand-held teams.

Most teams are effective at identification of high emitting sites with site-level emissions ranking effectiveness ranged between $43 \%$ to $70 \%$ of OGI rankings, pointing to their potential use as screening tools. The ability to distinguish between vents and leaks (fugitive emissions) could be beneficial for emissions mitigation programs. Without classification of emissions, sites with 'allowed' high venting volumes might be targeted for close range follow-up while sites with leaks but lower overall emissions could be missed. However, except for hand-held teams, no other team consistently identified whether the emissions were from leaks or vents. One way to address this issue would be to cap site-level emissions under regulations - combination of venting and leaks - and use asset-wide emissions average to determine penalties. In that 
scenario, screening technologies could be deployed for identification of non-compliant facilities for close-range follow-up, but they will need to improve their absolute quantification accuracy.

Many of the technologies tested in the AMFC program show promise for future deployment as part of regulatory LDAR programs. While these results provide critical insight into field challenges encountered by new technologies, it does not provide recommendations on future use (SI section 7). Stakeholders should carefully consider the tradeoffs identified here such as survey speed, quantification accuracy, and spatial resolution before choosing a specific solution. Models such as FEAST and LDAR-Sim can help operators and regulators evaluate new technologies in a systematic manner and achieve cost-effective methane emissions mitigation [49]-[51]. The AMFC provides critical insights to researchers, operators, and regulators on the challenges of conducting a field trial for new technologies at producing O\&G facilities.

\section{Acknowledgements}

Financial support for this research was provided by the Alberta Upstream Petroleum Research Fund and Harrisburg University of Science and Technology. The authors would like to thank Petroleum Technology Alliance Canada and industry participants for providing site access for the study, and critical feedback during the field trial program. We thank Davis Safety Consulting Inc. for conducting the baseline OGI survey in this study. Any opinions, findings, and conclusions or recommendations expressed in this material are those of the author(s) and do not necessarily reflect the views of the Alberta Upstream Petroleum Research Fund, Petroleum Technology Alliance Canada, or Harrisburg University of Science and Technology.

\section{References}

[1] S. Hamburg et al., "Methane Emissions From the U.S. Oil and Natural Gas Supply Chain: Climate and Policy Implications," AGUFM, vol. 2018, pp. GC41A-02, 2018.

[2] Intergovernmental Panel on Climate Change, Climate Change 2014 Mitigation of Climate Change. Cambridge University Press, 2014.

[3] K. Zickfeld, S. Solomon, and D. M. Gilford, "Centuries of thermal sea-level rise due to anthropogenic emissions of short-lived greenhouse gases," Proc. Natl. Acad. Sci. U. S. A., vol. 114, no. 4, pp. 657-662, Jan. 2017.

[4] A. A. Roy, P. J. Adams, and A. L. Robinson, "Air pollutant emissions from the development, production, and processing of Marcellus Shale natural gas," J. Air Waste Manag. Assoc., vol. 64, no. 1, pp. 19-37, Jan. 2014.

[5] D. R. Tyner and M. R. Johnson, "A Techno-Economic Analysis of Methane Mitigation Potential from Reported Venting at Oil Production Sites in Alberta," Environ. Sci. Technol., vol. 52, no. 21, pp. 12877-12885, 2018.

[6] Alvarez et al., "Assessment of methane emissions from the US oil and gas supply chain," Science (80-. )., vol. 361, pp. 186-188, 2018.

[7] M. R. Johnson, D. R. Tyner, S. Conley, S. Schwietzke, and D. Zavala-Araiza, "Comparisons of Airborne Measurements and Inventory Estimates of Methane Emissions in the Alberta Upstream Oil and Gas Sector," Environ. Sci. Technol., vol. 51, no. 21, pp. 13008-13017, Nov. 2017.

[8] E. Chan et al., "Eight-Year Estimates of Methane Emissions from Oil and Gas Operations in Western Canada Are Nearly Twice Those Reported in Inventories," Environ. Sci. Technol., vol. 21, p. acs.est.0c04117, Nov. 2020.

[9] A. P. Ravikumar and A. R. Brandt, "Designing better methane mitigation policies: The challenge of distributed small sources in the natural gas sector," Environ. Res. Lett., vol. 12, no. 4, 2017.

[10] J. Trudeau, B. Obama, and E. P. Nieto, "Leaders' Statement on a North American Climate, Clean Energy, and Environment Partnership | Prime Minister of Canada," 2016. [Online]. Available: 
https://pm.gc.ca/en/news/statements/2016/06/29/leaders-statement-north-american-climate-cleanenergy-and-environment. [Accessed: 20-Apr-2020].

[11] Environment and Climate Change Canada, "Canada's methane regulations for the upstream oil and gas sector - Canada.ca," 2020. [Online]. Available: https://www.canada.ca/en/environmentclimate-change/services/canadian-environmental-protection-act-registry/proposed-methaneregulations-additional-information.html. [Accessed: 17-Apr-2020].

[12] AER, "Directive 060 (Effective 2020)," no. December 2018, p. 124, 2018.

[13] California Air Resources Board, Oil and Gas Methane Regulation. United States.

[14] Colorado Government, "Oil \& gas compliance and recordkeeping | Department of Public Health and Environment.” [Online]. Available: https://www.colorado.gov/pacific/cdphe/air/oil-and-gascompliance. [Accessed: 10-May-2020].

[15] A. P. Ravikumar et al., "Repeated leak detection and repair surveys reduce methane emissions over scale of years," Environ. Res. Lett., vol. 15, no. 3, p. 034029, 2020.

[16] K. Rashid, A. Speck, T. P. Osedach, D. V. Perroni, and A. E. Pomerantz, "Optimized inspection of upstream oil and gas methane emissions using airborne LiDAR surveillance," Appl. Energy, vol. 275, p. 115327, Oct. 2020.

[17] D. Zavala-Araiza et al., "Super-emitters in natural gas infrastructure are caused by abnormal process conditions," Nat. Commun., vol. 8, no. 1, pp. 1-10, Jan. 2017.

[18] A. P. Ravikumar et al., "Repeated leak detection and repair surveys reduce methane emissions over scale of years," Environ. Res. Lett., vol. 15, no. 3, p. 034029, Mar. 2020.

[19] T. Fox et al., "A methane emissions reduction equivalence framework for alternative leak detection and repair programs," vol. 7, no. 1, p. 30, Jul. 2019.

[20] T. Fox, T. Barchyn, D. Risk, A. Ravikumar, and C. Hugenholtz, "A review of close-range and screening technologies for mitigating fugitive methane emissions in upstream oil and gas," Environ. Res. Lett., vol. 14, no. 5, 2019.

[21] A. P. Ravikumar et al., "Single-blind inter-comparison of methane detection technologies - results from the Stanford/EDF Mobile Monitoring Challenge," Elem Sci Anth, vol. 7, no. 1, p. 37, Sep. 2019.

[22] US Department of Energy, "ARPA-E's Methane Observation Networks with Innovative Technology to Obtain Reductions (MONITOR) program.” [Online]. Available: https://arpae.energy.gov/?q=arpa-e-programs/monitor. [Accessed: 14-Sep-2020].

[23] E. D. Sherwin, Y. Chen, A. Ravikumar, and A. Brandt, "Single-blind test of airplane-based hyperspectral methane detection via controlled releases," 2020.

[24] C. S. Bell, T. Vaughn, and D. Zimmerle, "Evaluation of next generation emission measurement technologies under repeatable test protocols," Elem Sci Anth, vol. 8, no. 1, p. 32, Jul. 2020.

[25] E. Atherton et al., "Mobile measurement of methane emissions from natural gas developments in northeastern British Columbia, Canada," Atmos. Chem. Phys., vol. 17, no. 20, pp. 12405-12420, Oct. 2017.

[26] J. G. Englander, A. R. Brandt, S. Conley, D. R. Lyon, and R. B. Jackson, “Aerial Interyear Comparison and Quantification of Methane Emissions Persistence in the Bakken Formation of North Dakota, USA,” Environ. Sci. Technol., vol. 52, no. 15, pp. 8947-8953, Aug. 2018.

[27] D. R. Lyon, R. A. Alvarez, D. Zavala-Araiza, A. R. Brandt, R. B. Jackson, and S. P. Hamburg, "Aerial Surveys of Elevated Hydrocarbon Emissions from Oil and Gas Production Sites," Environ. Sci. Technol., vol. 50, no. 9, pp. 4877-4886, May 2016.

[28] C. Frankenberg et al., "Airborne methane remote measurements reveal heavytail flux distribution in Four Corners region,” Proc. Natl. Acad. Sci. U. S. A., vol. 113, no. 35, pp. 9734-9739, Aug. 2016.

[29] L. Golston et al., "Natural Gas Fugitive Leak Detection Using an Unmanned Aerial Vehicle: Localization and Quantification of Emission Rate," Atmosphere (Basel)., vol. 9, no. 9, p. 333, Aug. 2018. 
[30] B. J. Nathan et al., "Near-Field Characterization of Methane Emission Variability from a Compressor Station Using a Model Aircraft," Environ. Sci. Technol., vol. 49, no. 13, pp. 78967903, Jul. 2015.

[31] D. Zavala-Araiza et al., "Methane emissions from oil and gas production sites in Alberta, Canada," Elementa, vol. 6, 2018.

[32] T. Barchyn, C. H. Hugenholtz, S. Myshak, and J. Bauer, "A UAV-based system for detecting natural gas leaks," J. Unmanned Veh. Syst., p. juvs-2017-0018, Oct. 2017.

[33] D. J. Jacob et al., "Satellite observations of atmospheric methane and their value for quantifying methane emissions," Atmos. Chem. Phys., vol. 16, no. 22, pp. 14371-14396, Nov. 2016.

[34] M. Alexe et al., "Inverse modelling of CH4 emissions for 2010-2011 using different satellite retrieval products from GOSAT and SCIAMACHY," Atmos. Chem. Phys., vol. 15, no. 1, pp. 113133, Jan. 2015.

[35] D. H. Cusworth et al., "Detecting high-emitting methane sources in oil/gas fields using satellite observations," Atmos. Chem. Phys., vol. 18, no. 23, pp. 16885-16896, Nov. 2018.

[36] Y. Zhang et al., "Satellite-Observed Changes in Mexico's Offshore Gas Flaring Activity Linked to Oil/Gas Regulations," Geophys. Res. Lett., vol. 46, no. 3, pp. 1879-1888, Feb. 2019.

[37] Y. Zhang et al., "Quantifying methane emissions from the largest oil-producing basin in the United States from space," Sci. Adv., vol. 6, no. 17, p. eaaz5120, Apr. 2020.

[38] D. J. Varon et al., "Satellite Discovery of Anomalously Large Methane Point Sources From Oil/Gas Production," Geophys. Res. Lett., vol. 46, no. 22, pp. 13507-13516, Nov. 2019.

[39] S. Pandey et al., "Satellite observations reveal extreme methane leakage from a natural gas well blowout," Proc. Natl. Acad. Sci. U. S. A., vol. 116, no. 52, pp. 26376-26381, Dec. 2019.

[40] J. A. de Gouw et al., "Daily Satellite Observations of Methane from Oil and Gas Production Regions in the United States," Sci. Rep., vol. 10, no. 1, pp. 1-10, Dec. 2020.

[41] A. P. Ravikumar, J. Wang, and A. R. Brandt, "Are Optical Gas Imaging Technologies Effective for Methane Leak Detection?,” Environ. Sci. Technol., vol. 51, no. 1, pp. 718-724, 2017.

[42] Clearstone Engineering Ltd. and Carleton University, "Update of Equipment, Component and Fugitive Emission Factors for Alberta Upstream Oil and Gas," Calgary, AB, 2018.

[43] B. Inc., "HI FLOW Sampler: For Natural Gas Leak Rate Measurement (Instruction 0055-9017)," $5,563,335$ and 6,489,787, 2015.

[44] M. Omara, M. R. Sullivan, X. Li, R. Subramian, A. L. Robinson, and A. A. Presto, "Methane Emissions from Conventional and Unconventional Natural Gas Production Sites in the Marcellus Shale Basin," Environ. Sci. Technol., vol. 50, no. 4, pp. 2099-2107, Feb. 2016.

[45] A. R. Brandt et al., "Methane Leaks from Natural Gas Systems Follow Extreme Distributions," Environ. Sci. Technol., vol. 50, no. 22, pp. 12512-12520, Nov. 2016.

[46] J. Liggio et al., "Measured Canadian oil sands CO 2 emissions are higher than estimates made using internationally recommended methods," Nat. Commun., vol. 10, no. 1, pp. 1-9, Dec. 2019.

[47] T. L. Vaughn et al., "Temporal variability largely explains top-down/bottom-up difference in methane emission estimates from a natural gas production region," Proc. Natl. Acad. Sci. U. S. A., vol. 115, no. 46, pp. 11712-11717, Nov. 2018.

[48] D. T. Allen, F. J. Cardoso-Saldaña, and Y. Kimura, "Variability in Spatially and Temporally Resolved Emissions and Hydrocarbon Source Fingerprints for Oil and Gas Sources in Shale Gas Production Regions,” Environ. Sci. Technol., vol. 51, no. 20, pp. 12016-12026, Oct. 2017.

[49] C. E. Kemp, A. P. Ravikumar, and A. R. Brandt, "Comparing Natural Gas Leakage Detection Technologies Using an Open-Source 'virtual Gas Field' Simulator,” Environ. Sci. Technol., vol. 50, no. 8, pp. 4546-4553, May 2016.

[50] C. Kemp and A. Ravikumar, "New Technologies can Cost-effectively Reduce Oil and Gas Methane Emissions, but Policies will Require Careful Design to Establish Mitigation Equivalence," 2021.

[51] T. A. Fox, M. Gao, T. E. Barchyn, Y. L. Jamin, and C. H. Hugenholtz, "An agent-based model for 
estimating emissions reduction equivalence among leak detection and repair programs," J. Clean. Prod., vol. 282, p. 125237, Feb. 2021.

[52] L. S. Rothman et al., "The HITRAN2012 molecular spectroscopic database," J. Quant. Spectrosc. Radiat. Transf., vol. 130, pp. 4-50, 2013.

[53] A. E. S. Green, R. P. Singhal, and R. Venkateswar, "Analytic extensions of the gaussian plume model," J. Air Pollut. Control Assoc., vol. 30, no. 7, pp. 773-776, 1980.

[54] F. Pasquill, "The Estimation of the Dispersion of Windborne Material.," Meteorol. Mag., vol. 90, pp. 33-49, 1961.

[55] F. A. Gifford, "Use of Routine Meteorological Observations for Estimating Atmospheric Dispersion," Nucl. Saf., vol. 2, no. 4, pp. 47-51, 1961.

[56] Y. Y. Cui et al., "Top-down estimate of methane emissions in California using a mesoscale inverse modeling technique: The South Coast Air Basin," J. Geophys. Res. Atmos., vol. 120, no. 13, pp. 6698-6711, Jul. 2015.

[57] D. Zimmerle, T. Vaughn, C. Bell, K. Bennett, P. Deshmukh, and E. Thoma, "Detection Limits of Optical Gas Imaging for Natural Gas Leak Detection in Realistic Controlled Conditions," Environ. Sci. Technol., vol. 54, no. 18, pp. 11506-11514, Sep. 2020. 


\section{Field Performance of New Methane Detection Technologies: Results from the Alberta Methane Field Challenge Supplementary Information}

\section{Table of Contents}

S.1 Application process \& data collection............................................................................. 0

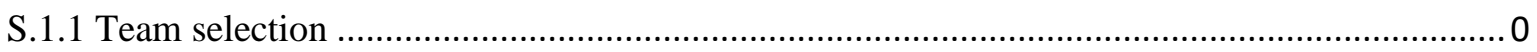

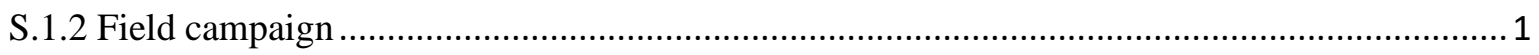

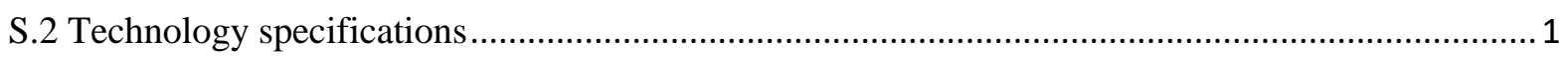

S.3 Heath Consultants Ltd. - fixed sensor ............................................................................... 6

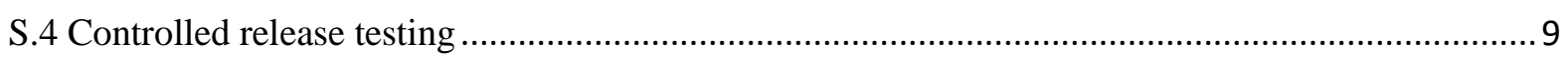

S.4.1. Controlled release test of Quantitative Optical Gas Imaging instrument..............................10

S.4.2. Controlled release test results from participating teams ..................................................... 14

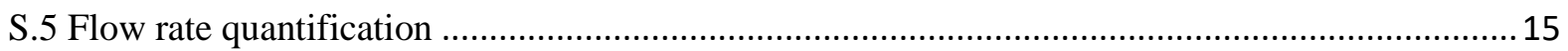

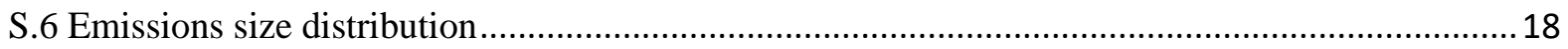

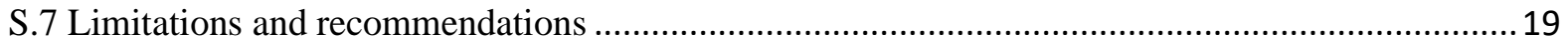

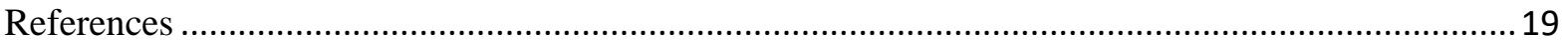

$1 \quad$ S.1 Application process \& data collection

2 S.1.1 Team selection

3 Alberta Methane Field Challenge (AMFC) participants were selected through a rigorous

4 application process comprised of two main steps. First, prospective participants were invited to

5 submit a detailed application with information on their organization, technology and method

6 specifications, and business plan and costs of their system. Next, the selection team - comprising

7 of scientists, project managers, regulators, and industry advisors - rigorously evaluated the teams

8 against established criteria including technological capabilities, survey speed, prior controlled

9 release test or real-world field experience, technology readiness and scalability, business factors,

10 and logistical considerations to allow for a safe, concurrent, large-scale field trial. Thus, the

11 number of teams that could be selected for the field campaign with similar platforms (e.g., aerial

12 systems) were limited by safety considerations, irrespective of the outcome of their evaluation. 


\section{S.1.2 Field campaign}

The information in this section is provided to assist in the development and execution of future field campaigns. It includes details on team orientation, in-field communications, site scheduling, and data integrity and handling procedures.

Orientation: A day long orientation was mandatory for participating teams in both AMFC campaigns. The orientation included information on site permitting, environmental health and safety certifications, emergency protocols, appropriate safety gear, and site-access agreements for participating teams to get on producing oil and gas sites for measurements.

In-field communication: Communications between participating teams and the research team were handheld through a secure mobile text-based communication channel (Slack). Teams used this to announce their arrival and departure from sites so that other participating teams could plan their daily site visit accordingly. This also helped alert teams of any access or safety issues at one or more sites during the day such as muddy or slippery road conditions, locked gates at site entrances, presence of livestock, and other logistical issues. The study team also used the Slack channel to warn participating teams of changing weather conditions, give 'shelter in place' orders, or to stop surveys based on weather radar information.

Site scheduling: AMFC Phase 1 was conducted between June 11-21, 2019, and AMFC Phase 2 was conducted between November 14-24, 2019. In all, there were 49 sites in phase 1 and 50 sites in phase 2 , of which 45 overlapped in both phases. Four sites from phase 1 were not included in phase 2, while five new sites were added due to ease of access during winter conditions. Coordination of site visits between the OGI crew collecting baseline emissions data and participating teams was essential to compare data. Researchers prepared a detailed field schedule for each day of the campaign, which accounted for several factors including travel time between sites, survey speed, and site size. Every morning, the participating teams attended a briefing led by the researchers and the OGI team to go over field schedule, plan the order of team site visits, and discuss any issues that might have come up on prior field days. Each day, the two OGI teams surveyed a pre-selected list of 3-6 sites from the field schedule that were 'mandatory' for all teams to visit on the same day. Teams could survey additional sites after completing surveys at the mandatory sites.

Data handling and reporting: Each team submitted emissions data in a specified excel template that included information on weather, survey time, emissions detected, localization, emission rate quantification, and any observations not included in the standard format. In addition, the teams were asked to also submit their typical field survey data reports as would be provided to customers, along with any supporting evidence for the data (e.g., $\mathrm{kmz}$ files or images and videos etc.). The teams also submitted daily field logs with information on survey times, sites visited, and any safety or logistical observations which could be useful for other teams visiting those sites.

\section{S.2 Technology specifications}

Table S1 shows the technology specifications for each participating team as reported in their application. These values were self-reported and up to date at the time of the application (June 2019 and November 2019). The data provided here correspond to those that can be publicly released by the participating teams. No proprietary data were requested as part of the application process. Given that the main goal of the study is to compare the performance of technologies 
under pre-determined criteria, a thorough understanding of the underlying sensor is not essential.

57 Regulators, operators, and other academics may find the data in this study valuable in making

58 decisions about technology choices, irrespective of specific sensors used by the participating teams. However, specifications for each technology may differ based on more recent testing.

60 In addition to information on the team, technology performance, testing data, and business

61 information, data on the following critical parameters were requested.

a. Technology team: Column A gives the name of the technology team, while Column B describes the platform of the technology team - drone, plane, truck, or hand-held.

b. Detection level: Column $\mathrm{C}$ describes the detection level of the technology teams -sitelevel, equipment-level or component-level.

c. Sensor physical mechanism: Column D describes the physical mechanism underlying the methane sensor such as hyperspectral infrared imaging, or cavity ring-down absorption spectroscopy, etc.

d. Type of measurement: Column E collected data on measurement type - point-source, continuous, and the temporal resolution of data.

e. Detection limits: Column F describes the sensitivity of the methane sensor in units of native resolution such as parts per billion (ppb) or minimum detection limits in flow rates as measured in controlled release tests. It also includes the distances and meteorological conditions in which the technologies have been tested.

f. Sensor dynamic range: Column $\mathrm{G}$ describes the dynamic measurement range of the sensor. 
Table S4: Technology team specifications as reported in the AMFC applications.

\begin{tabular}{|c|c|c|c|c|c|c|}
\hline $\begin{array}{l}\text { Technology } \\
\text { team (A) }\end{array}$ & $\begin{array}{l}\text { Platform } \\
\text { (B) }\end{array}$ & $\begin{array}{l}\text { Detection } \\
\text { level }(C)\end{array}$ & $\begin{array}{l}\text { Sensor physical } \\
\text { mechanism (D) }\end{array}$ & $\begin{array}{l}\text { Type of measurement } \\
(\mathrm{E})\end{array}$ & Detection limits (F) & $\begin{array}{c}\text { Dynamic range } \\
\text { (G) }\end{array}$ \\
\hline $\begin{array}{l}\text { Aerometrix } \\
\text { Inc. }\end{array}$ & Drone & Equipment & $\begin{array}{l}\text { GHGMapper }{ }^{\mathrm{TM}} \text { uses } \\
\text { patented Mid-IR, } \\
\text { Open Path Laser } \\
\text { Spectrometer } \\
\text { ('OPLS'). }\end{array}$ & $\begin{array}{l}\text { Mobile, optical spectrometer, } \\
\text { fixed } 10 \mathrm{~Hz} \text { data collection } \\
\text { rate }\end{array}$ & $\begin{array}{l}\text { Confirmed minimum } \\
\text { detection limit for methane is } \\
\text { better than } 0.1 \mathrm{scfh}(\sim 2 \mathrm{~g} / \mathrm{h}) \text {, } \\
\text { based on a distance of } 10 \mathrm{~m} \\
\text { from the leak. Tests have } \\
\text { been conducted under hot and } \\
\text { freezing, dry and damp } \\
\text { conditions }\end{array}$ & $\begin{array}{l}\text { GHGMapperTM is } \\
\text { configured to measure } \\
\text { methane from } \sim 100 \mathrm{ppb} \\
\text { to } \sim 50 \mathrm{ppm} \text { at } 10 \mathrm{~Hz}\end{array}$ \\
\hline Seekops Inc. & Drone & Equipment & $\begin{array}{l}\text { Miniature tunable } \\
\text { laser spectrometer } \\
\text { (150 grams with } \\
\text { electronics) } \\
\text { operating in the } \\
\text { midwave infrared } \\
\text { (MWIR) spectral } \\
\text { region }\end{array}$ & $\begin{array}{l}\text { Typical data report rates are } \\
4 \mathrm{~Hz} \text { but can be increased up } \\
\text { to } 100 \mathrm{~Hz}\end{array}$ & $\begin{array}{l}\text { Sensor constantly measures } \\
\text { background methane } \\
(\sim 1.9 \mathrm{ppm}) \text {. The sensor can } \\
\text { measure fluctuations at } 10 \\
\text { parts-per-billion (ppb) above } \\
\text { background. The sensor } \\
\text { performance has been } \\
\text { verified in extreme cold } \\
\left(<0^{\circ} \mathrm{C}\right) \text { and hot conditions } \\
\left(>48^{\circ} \mathrm{C}\right)\end{array}$ & $\begin{array}{l}\text { The SeekIR sensor can } \\
\text { measure methane } \\
\text { concentrations from } \\
0.01-10,000 \text { parts-per- } \\
\text { million (ppm) above } \\
\text { background }\end{array}$ \\
\hline $\begin{array}{l}\text { Bridger } \\
\text { Photonics }\end{array}$ & Plane & Equipment & $\begin{array}{l}\text { Spatially scanned } \\
\text { airborne LiDAR } \\
\text { (active remote } \\
\text { sensor). Gas } \\
\text { concentration } \\
\text { measurements based } \\
\text { on wavelength } \\
\text { modulation } \\
\text { spectroscopy at } \\
1650 \mathrm{~nm} \\
\text { wavelength }\end{array}$ & $\begin{array}{l}\text { Provides gas concentration } \\
\text { imagery and flow rates for } \\
\text { detected leaks on a periodic } \\
\text { basis with frequency } \\
\text { determined by the desired } \\
\text { rate of aircraft/sensor } \\
\text { deployment }\end{array}$ & $\begin{array}{l}\text { Flow rate detection limits } \\
\text { depend on many factors } \\
\text { including flight altitude, flight } \\
\text { speed, wind speed, etc. For } \\
\text { example, at } 150 \text { meters AGL, } \\
130 \mathrm{~km} / \mathrm{hr} \text { flight speed, with } 5 \\
\mathrm{~km} / \mathrm{hr} \text { wind speed, they } \\
\text { achieved a flow rate detection } \\
\text { limit (i.e. } 50 \% \text { detection } \\
\text { probability) of } 10 \mathrm{lpm} \text {. } \\
\text { GML's concentration } \\
\text { detection limits depend on } \\
\text { flight parameters, but not } \\
\text { wind speed }\end{array}$ & $\begin{array}{l}\text { Concentration detection } \\
\text { limit to } 50,000 \text { ppm-m. } \\
\text { Flow Rate detection } \\
\text { limited by concentration } \\
\text { limit. Methane detection } \\
\text { possible for } \\
\text { concentrations above } \\
50,000 \text { ppm-m but } \\
\text { measurement accuracy } \\
\text { is degraded }\end{array}$ \\
\hline $\begin{array}{l}\text { Sander } \\
\text { Geophysics }\end{array}$ & Plane & Site & $\begin{array}{l}\text { SGL's methane } \\
\text { sensor collects } \\
\text { intake air through an }\end{array}$ & $\begin{array}{l}\text { The system measures at } \\
\text { fixed-rate, recording } \\
\text { methane concentration at up }\end{array}$ & $\begin{array}{l}\text { Sensor's specified detection } \\
\text { limits are 0-1000 ppm. } \\
\text { Sander has flown between }\end{array}$ & $\begin{array}{l}\text { The sensor's specified } \\
\text { range is } 0.01-100 \mathrm{ppm}\end{array}$ \\
\hline
\end{tabular}




\begin{tabular}{|c|c|c|c|c|c|c|}
\hline & & & $\begin{array}{l}\text { inlet port mounted } \\
\text { externally on the } \\
\text { survey aircraft and } \\
\text { pumps the air } \\
\text { through a particle } \\
\text { separator filter to an } \\
\text { off-axis integrated } \\
\text { cavity output } \\
\text { spectroscopy (OA- } \\
\text { ICOS) analyzer }\end{array}$ & $\begin{array}{l}\text { to } 20 \mathrm{~Hz} \text { ( } 1 \mathrm{~Hz} \text { commonly } \\
\text { used). The initial processing } \\
\text { results in a measure of the } \\
\text { methane concentration } \\
\text { enhancement along the flight } \\
\text { lines. Inversion is then } \\
\text { performed to calculate the } \\
\text { ground locations and mass } \\
\text { emission rates of sources }\end{array}$ & $\begin{array}{l}\text { 500' and 1000' above ground } \\
\text { level (AGL), ideally conduct } \\
\text { surveys at 500' AGL. In } \\
\text { survey configuration, Sander } \\
\text { estimates a lower detection } \\
\text { limit of approximately } \\
\sim 30 \mathrm{~kg} / \mathrm{hr} \text { for a source at } \\
\text { ground level when flying at } \\
\text { 500'AGL }\end{array}$ & \\
\hline Tecvalco Ltd. & Hand-held & Component & $\begin{array}{l}\text { Tunable diode laser } \\
\text { absorption } \\
\text { spectroscopy }\end{array}$ & $\begin{array}{l}\text { Gas-Trac LZ30 - fixed at } \\
100 \mathrm{~ms} \\
\text { Gas-Trac LZ50 - fixed at } \\
100 \mathrm{~ms} \\
\text { Gas-Trac FPL - collected at } \\
\text { 1Hz. Data output is } \\
\text { adjustable: } 1 \text { second, 10- } \\
\text { second average, and 1- } \\
\text { minute average. } \\
\text { Hawk Vent Gas Meter - } \\
\text { single point. Direct } \\
\text { measurement with high } \\
\text { accuracy and data logging }\end{array}$ & $\begin{array}{l}\leq 5 \mathrm{ppm}-\mathrm{m} @ 15 \mathrm{~m}, \leq 10 \mathrm{ppm}- \\
\mathrm{m} @ 30 \mathrm{~m} \\
\leq 5 \mathrm{ppm}-\mathrm{m} @ 15 \mathrm{~m}, \leq 10 \mathrm{ppm}- \\
\mathrm{m} @ 50 \mathrm{~m} \\
\text { Minimum detection limit is } \\
1.0 \text { SCFH at } 40 \mathrm{~m} \text { downwind } \\
\text { from leak. Native detection } \\
\text { limit from } 5 \text { ppm-m to } \\
9999.99 \text { ppm-m } \\
\text { Flow rates from } 0.5 \text { acf/day to } \\
6000 \text { scf/day at } 0.5 " \mathrm{H} 2 \mathrm{O} \\
\text { differential }\end{array}$ & $\begin{array}{l}\leq 5 \mathrm{ppm}-\mathrm{m} @ \\
15 \mathrm{~m} / \leq 10 \mathrm{ppm}-\mathrm{m} @ 30- \\
50 \mathrm{~m} \text { to } 50,000 \mathrm{ppm}-\mathrm{m} \\
\text { with good reflectivity. } \\
\text { Dependent on optical } \\
\text { path length: } 1 \text { meter } \\
\text { (absolute minimum } \\
\text { path): 5ppm to } 9999.99 \\
\text { ppm (1 vol \%), } 10 \\
\text { meters: } 0.5 \text { ppm to } \\
\text { 999.99 ppm (0.1 vol \%), } \\
\text { meters: (absolute } \\
\text { maximum path): } 0.125 \\
\text { ppm to } 249.99 \text { ppm }\end{array}$ \\
\hline $\begin{array}{l}\text { FLIR } \\
\text { Systems } \\
\text { Canada }\end{array}$ & Hand-held & Component & $\begin{array}{l}\text { Uncooled infrared } \\
\text { camera }\end{array}$ & $\begin{array}{l}\text { No measurement. Detection } \\
\text { only. Continuous, requiring } \\
\text { human viewing of the image }\end{array}$ & $\begin{array}{l}100 \text { ppm*m Noise Equivalent } \\
\text { Concentration Limit, in a lab } \\
\text { environment at } 1 \text { meter } \\
\text { distance with standard lens, } \\
20 \mathrm{C} \text { ambient temperature, } 10 \\
\mathrm{C} \text { delta T to background }\end{array}$ & NA \\
\hline $\begin{array}{l}\text { Heath } \\
\text { Consultants } \\
\text { Ltd. }\end{array}$ & Hybrid & Component & $\begin{array}{l}\text { OMD: Open path IR } \\
\text { sensors based on } \\
\text { Etalon spectroscopy } \\
\text { RMLD: Backscatter } \\
\text { Tunable Diode } \\
\text { Laser Absorption }\end{array}$ & $\begin{array}{l}\text { Continuous data at } 10 \\
\text { samples/sec, transmitted } \\
\text { wirelessly to cloud. } \\
\text { Continuous measurement of } \\
\text { column-integrated methane. } \\
\text { Data rate is } 10 \text { points/second. } \\
\text { Can provide eak rate }\end{array}$ & $\begin{array}{l}<1 \mathrm{scfh} \text {. Wind from light to } \\
30 \mathrm{mph} .0 .5 \mathrm{ppm} \text {. } \\
\text { Min } ~ 0.25 \mathrm{scfh}, \mathrm{Max}>1000 \\
\text { scfh. Distance up to } 30 \mathrm{~m} . \\
\text { Wind from light to } 10 \mathrm{mph} .3\end{array}$ & $\sim 10,000$. \\
\hline
\end{tabular}


Non-peer reviewed pre-print submitted to EarthArXiv

\begin{tabular}{|c|c|c|c|c|c|c|}
\hline & & & $\begin{array}{l}\text { Spectroscopy (b- } \\
\text { TDLAS) }\end{array}$ & $\begin{array}{l}\text { estimate combined with local } \\
\text { wind data }\end{array}$ & $\begin{array}{l}\text { ppm-m, or average of } 300 \\
\text { ppb over } 10 \mathrm{~m} \text { optical path }\end{array}$ & \\
\hline $\begin{array}{l}\text { Heath } \\
\text { Consultants } \\
\text { Ltd. }\end{array}$ & Fixed & Site & $\begin{array}{l}\text { Long open-path } \\
\text { backscatter tunable } \\
\text { diode laser } \\
\text { absorption } \\
\text { spectroscopy }\end{array}$ & $\begin{array}{l}\text { continuous data at } 10 \\
\text { samples/sec transmitted } \\
\text { wirelessly to cloud. } \\
\text { Continuous measurement of } \\
\text { column-integrated methane } \\
\text { between transceiver and } \\
\text { distant backscatter target. } \\
\text { Temporal resolution is } 10 \mathrm{~Hz}\end{array}$ & $\begin{array}{l}\text { Min } ~ 1 \text { scfh, Max }>1000 \\
\text { scfh. Native detection limits: } \\
3 \text { ppm-m, or avg. } 30 \text { ppb over } \\
100 \text { m optical path, } 3 \text { ppb } \\
\text { over } 1000 \mathrm{~m} \text { range }\end{array}$ & $\sim 100,000$ \\
\hline $\begin{array}{l}\text { Altus } \\
\text { Geomatics } \\
\text { (now } \\
\text { GeoVerra) }\end{array}$ & Truck & Site & $\begin{array}{l}\text { Cavity Ring-Down } \\
\text { Spectroscopy } \\
\text { (CRDS). Altus uses } \\
\text { Picarro analyzers }\end{array}$ & $\begin{array}{l}\text { ExACT data (multi-gas, } \\
\text { GPS, meteorological) is } \\
\text { collected continuously at } \\
1 \mathrm{~Hz}\end{array}$ & $\begin{array}{l}\text { Lab conditions - min. } \\
\text { detection limit validated to } \\
0.2 \mathrm{gCH}_{4} / \mathrm{hr} \text { at wind } 3 \mathrm{~km} / \mathrm{hr} \text {, } \\
6 \mathrm{~m} \text { distance from emission } \\
\text { source using } 1000 \mathrm{ppm} \mathrm{CH}_{4} \\
\text { for testing. Max. detection } \\
\text { limit is undefined but related } \\
\text { to the maximum } \\
\text { concentration range of } \\
\text { Picarro } \mathrm{G} 2210-\mathrm{i} \mathrm{GHG} \\
\text { analyzer. } \mathrm{Native} \mathrm{detection} \\
\text { limits: } \mathrm{C}_{2} \mathrm{H}_{6} 0-100 \mathrm{ppm} ; \mathrm{CH}_{4} \\
1.5-30 \mathrm{ppm} ; \mathrm{CO}_{2} 300- \\
2000 \mathrm{ppm} ; \delta_{13} \mathrm{CH}_{4} 2-30 \mathrm{ppm}\end{array}$ & $\begin{array}{l}\text { The range of the Picarro } \\
\text { G2201-i is not impacted } \\
\text { by specific settings or } \\
\text { configurations }\end{array}$ \\
\hline $\begin{array}{l}\text { University of } \\
\text { Calgary }\end{array}$ & Truck & Equipment & $\begin{array}{l}\text { Open-path } \\
\text { wavelength } \\
\text { modulated } \\
\text { spectroscopy }\end{array}$ & $\begin{array}{l}\text { System collects data at } 10 \mathrm{~Hz} \\
\text { as the vehicle drives }\end{array}$ & $\begin{array}{l}\text { The methane sensor has no } \\
\text { absolute minimum or } \\
\text { maximum detection limit and } \\
\text { can function from } 0.0 \mathrm{ppmv} \\
\text { to approx } 40.0 \mathrm{ppmv} \text {, at } \\
\text { which point it 'ranges out' } \\
\text { and no longer produces } \\
\text { accurate information }\end{array}$ & $\begin{array}{l}\text { The dynamic range of } \\
\text { the sensor is not well } \\
\text { constrained }\end{array}$ \\
\hline
\end{tabular}




\section{S.3 Heath Consultants Ltd. - fixed sensor}

Heath Consultants Ltd. installed a fixed, continuous, solar-powered long open-path sensor based on backscatter Tunable Diode Laser Absorption Spectroscopy in June 2019. The fixed sensor is discussed in the supplementary information and not the main text given the nature of analysis required as compared to other technology teams which participated in the AMFC. The Heath team did not report quantified emissions rates or emissions attribution - the analysis presented here has been conducted by the authors of this paper. The following analysis illustrates the potential of fixed sensors to identify emissions, and the significant analytical work required to translate sensor readings into actionable information. Additional analysis and complex dispersion models are required to correctly identify emitting equipment and performance of the sensor but is beyond the scope of this paper.

The fixed sensor reports path-integrated concentration at $10 \mathrm{~Hz}$ frequency and data are stored to the cloud every 6 seconds. The backscatter target of the open-path sensor was installed approximately 22 meters $(\mathrm{m})$ away from the light source. Consequently, a background methane concentration of $1.8 \mathrm{ppm}$ along this path would result in a path-integrated concentration of about $40 \mathrm{ppm}-\mathrm{m}$. The sensor data were made available to the researchers in real-time and consisted of data on instantaneous and time-average concentration path-length, wind speed, and wind direction.

To derive site-specific information on leak location and emission rate, we use a Gaussian atmospheric dispersion model to reproduce the methane concentration path-length signature on the sensor for a given leak rate (flux). The plume concentration, $\varphi(X ; \mu)\left[\mathrm{g} / \mathrm{m}^{3}\right]$, is given by,

$\varphi(X ; \mu)=\frac{Q}{2 \pi \mu \sigma_{y}(x) \sigma_{z}(x)} \exp \left(\frac{\left(y-y_{0}\right)^{2}}{2 \sigma_{y}^{2}(x)}\right)\left[\exp \left(\frac{\left(z-z_{m}(x)\right)^{2}}{2 \sigma_{z}^{2}(x)}\right)+\exp \left(\frac{\left(z+z_{m}(x)\right)^{2}}{2 \sigma_{z}^{2}(x)}\right)\right]$

where, $Q$ is the flux $(\mathrm{g} / \mathrm{s}), \mu$ is the wind speed $(\mathrm{m} / \mathrm{s}), z$ is measured above ground, $y$ is the perpendicular downwind distance and $y_{0}$ is the leak source position, $\sigma_{y}(x)$ and $\sigma_{z}(x)$ are the dispersion coefficients of plume concentration based on Pasquill-Gifford atmospheric stability classes [53]-[55].

Knowing the approximate position of various potential emission sources at the site aids in attributing the methane enhancement to a piece of equipment or an equipment group (Figure S1). 


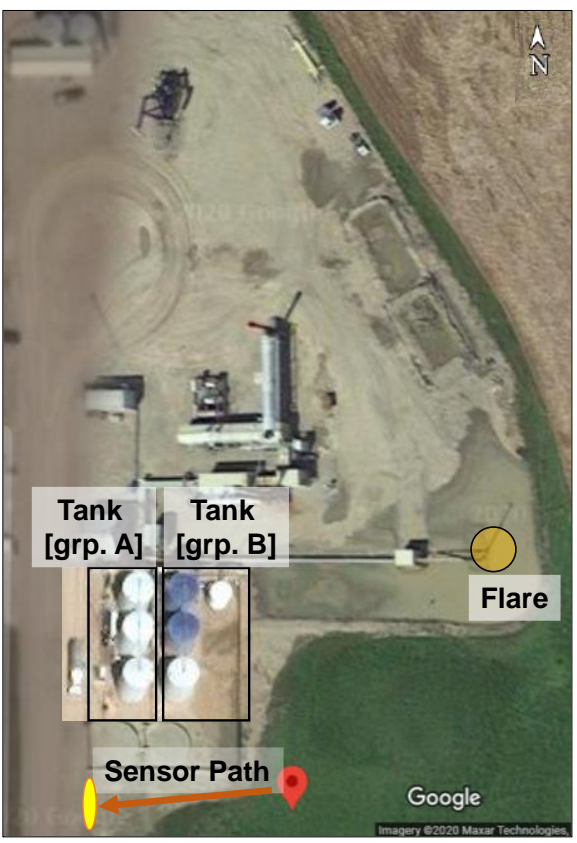

Figure S5: Heath fixed sensor site layout with location of sensor and major equipment on site overlaid on google earth base layer.

To model emissions from tanks (group A and B) and flare based on wind direction (Figure S2) we used Pasquill-Gifford atmospheric stability class B (moderately unstable) and assumed neutral buoyancy. Two wind speeds for November 27, 2019 were selected: median of $0.7 \mathrm{~m} / \mathrm{s}$ and $0.5 \mathrm{~m} / \mathrm{s}$ actual wind speed for concentration above $8 \mathrm{ppm}$ for when the 4 major spikes in concentration are detected by the sensor [54], [55].

The model estimates that a stable flux of $1 \mathrm{~g} / \mathrm{s}$ from the flare is detectable by the sensor when wind direction is between 20-80 degrees from the north under a given wind speed of $0.5 \mathrm{~m} / \mathrm{s}$. Thus, the peaks in emissions detected by the sensor at 40 and 55 degrees from the north could be attributable to the flare stack, with an almost identical peak concentration reading. To model emissions from the tanks, we used two locations - left (group A) and right (group B) and assumed a flux of $0.5 \mathrm{~g} / \mathrm{s}$ under two wind speeds. We estimate that tank emissions are detectable by the sensor between 280-360 degree from north and 0-60 degree from north assuming all other equipment north of the tanks is non-emitting. Consequently, the observed peak in emissions detected by the sensor at 30 degrees could be attributed to tank group B, while the peak at 300 degrees could be attributed to tank group A. Moreover, it is also likely that the peak at 10 degrees is a combination of emissions from either both tanks or one with a flux $>0.5 \mathrm{~g} / \mathrm{s}$. 


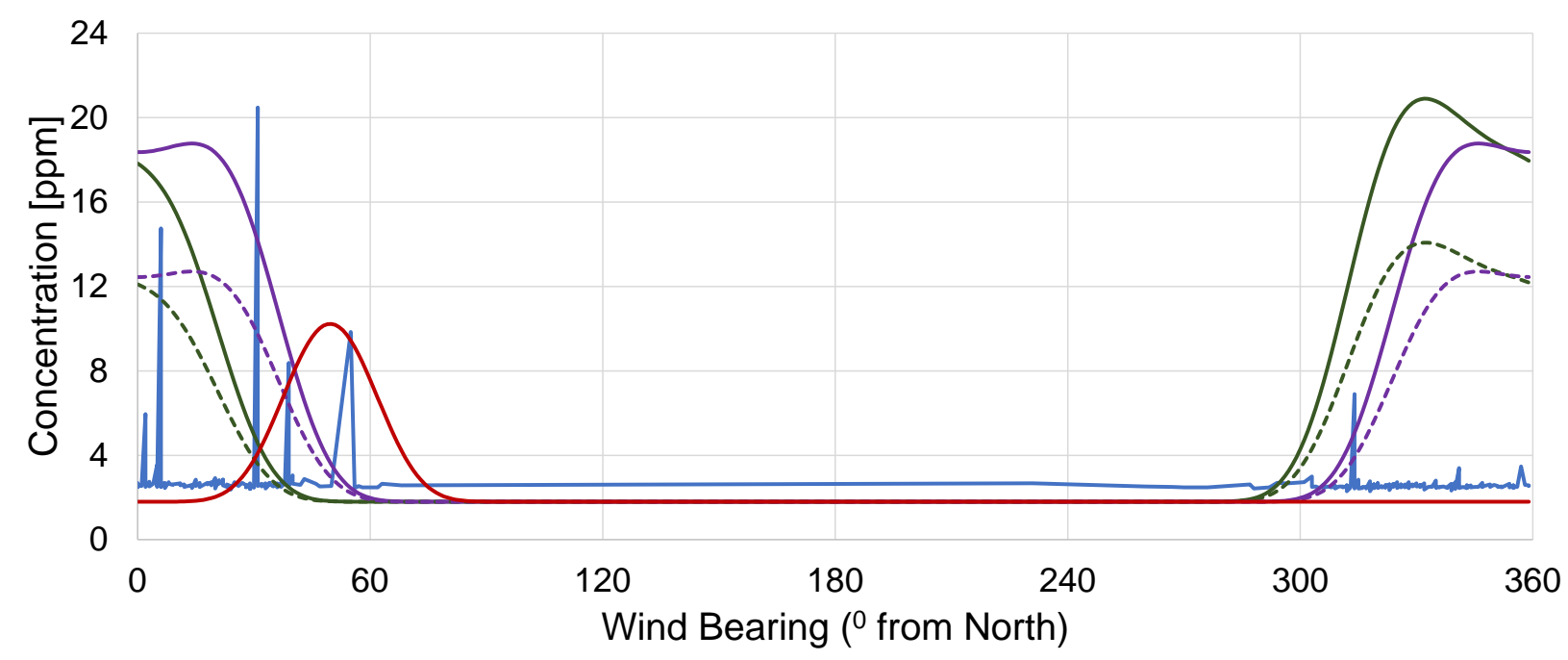

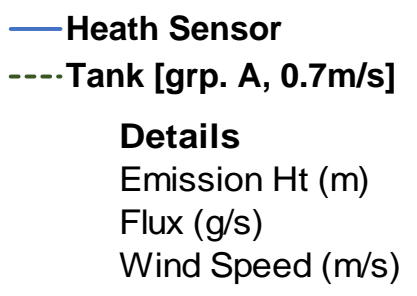

\section{—Tank [grp. A, 0.5m/s] -.-.Tank [grp. B, 0.7m/s]}

Tanks 10

0.5
—Tank [grp. B, 0.5m/s]

-Flare, $0.5 \mathrm{~m} / \mathrm{s}$

Flare 20 $0.5 \& 0.7$

Figure S6: Methane $\left(\mathrm{CH}_{4}\right)$ concentration in parts per million (ppm) for tanks and flare plotted against wind direction (degrees from north). The sensor is located at a height of $2 \mathrm{~m}$, and the reading (blue) is for average concentration every 5 minutes for November 27, 2019. Wind speed $0.5 \mathrm{~m} / \mathrm{s}$ is the actual speed when peaks were detected, $0.7 \mathrm{~m} / \mathrm{s}$ is the median wind speed for the day. Stability Class B is based on Pasquill-Gifford classes under given wind conditions. Neutral buoyancy is assumed for plume.

Beyond attributing concentration to possible leak sources, these data can be analyzed to explore the temporal behavior of methane emissions. The modeled emissions show that a stable continuous flux would result in a broad curve (as modeled) rather than the observed sharp peaks by the sensor. This likely points to the temporal variability of methane emissions from oil and gas facilities such that the concentrations recorded here are not continuous, but intermittent emissions. Figure S3 further shows the temporal variability of emissions concentration as detected by the sensor for a 10-day period between November 1-10, 2019. 


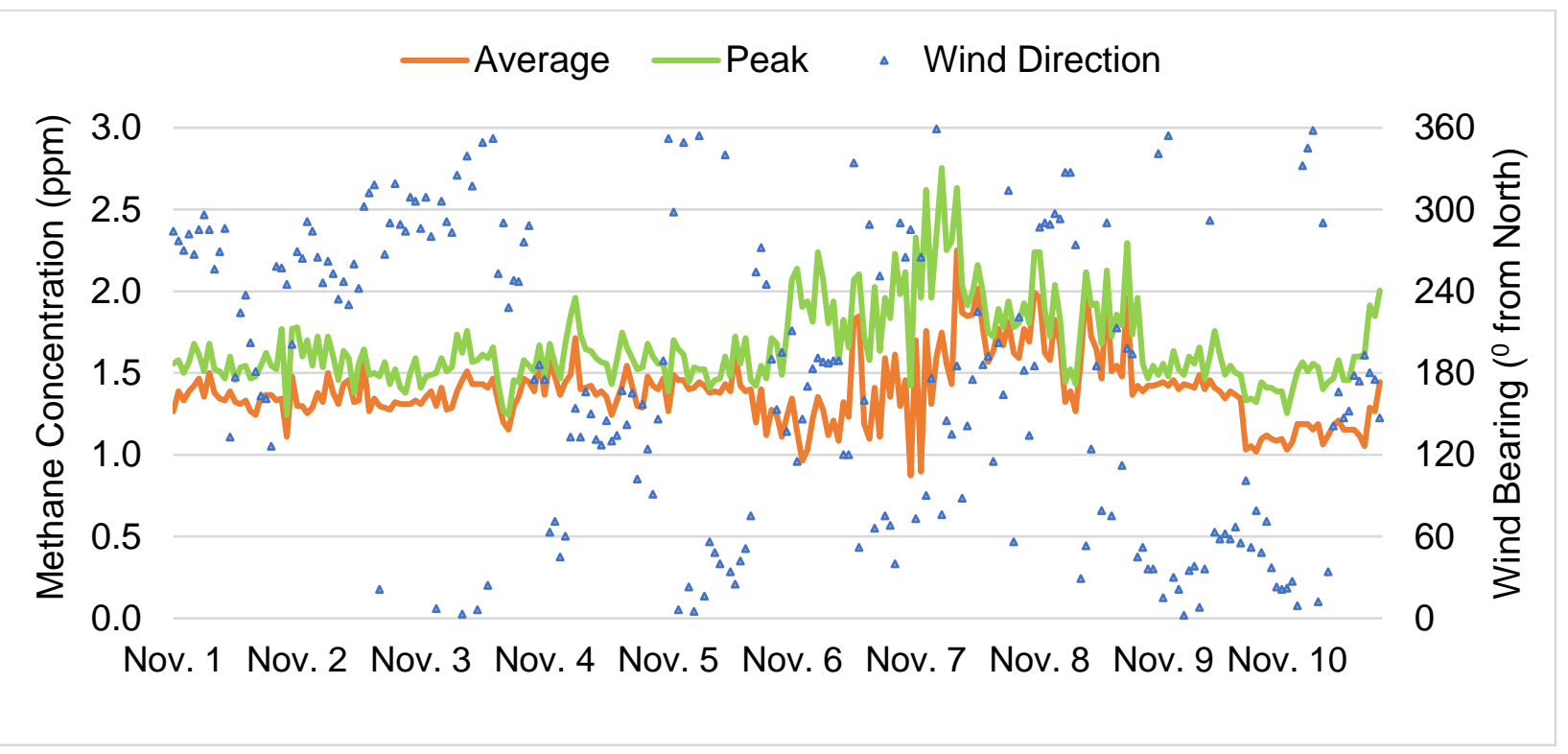

Figure S7: Methane $\left(\mathrm{CH}_{4}\right)$ concentration in parts per million (ppm) as detected by the sensor between November 1-10, 2019. Data were recorded every hour for average and peak ppm concentration. Wind direction is in degrees from north.

The analyzes presented here only seek to illustrate how data from continuous sensors could be used to identify the spatial and temporal behavior in methane emission. Precisely identifying emission sources and emission rates would require advanced dispersion modeling to account for local turbulence and temporal variation in emissions (e.g., [56]). Continuous monitoring may be critical in identifying intermittent emissions that could be missed by periodic LDAR surveys. While continuous monitoring sensors can provide high temporal resolution data on methane concentrations, significant analytical work is required to translate sensor readings into actionable information. Thus, effective use of continuous monitoring systems in an LDAR context will require significant analytical capabilities to direct follow-up inspection or repair.

\section{S.4 Controlled release testing}

Controlled release testing (CRT) was included in AMFC phase 2 (November), where known methane release rates were used to evaluate the quantification accuracy of QOGI and the participating technology teams. The CRT was not intended to exhaustively evaluate the performance parameters of a technology such as detection probability curves as conducted in prior studies [21], but rather to evaluate quantification ability across a wide range of emissions rates typically observed at oil and gas sites.

Nitrogen Technologies of Canada (NTOC) was contracted to assist with the controlled release tests. The CRT was set up on an open, undeveloped, non-operating oil and gas site located near the field campaign study area. Odorized gas, with a methane content of $89.86 \%$, was used throughout the experiment. The Omega FMA-1613A flow meter displaying pressure, temperature, and mass and volumetric flow was calibrated to use with methane. A heat exchanger regulated the gas temperature to near-ambient conditions. Each morning, NTOC staff ran a Zero CAL-CHECK to validate the flow meters calibration accuracy. 
The NTOC staff and researcher on site monitored flow rates continuously during all releases, and data were logged electronically at a 15 -second interval. These release rates were chosen to mimic both equipment-level and site-level emissions typically observed at operating oil and gas sites. The rates were based on the frequency for various release classes recorded by the OGI crew in the June AMFC campaign. The test rates spanned three orders of magnitude as shown in Figure S4 and ranged from a low of 30 standard cubic feet per hour (scfh) to a maximum of $2000 \mathrm{scfh}$.

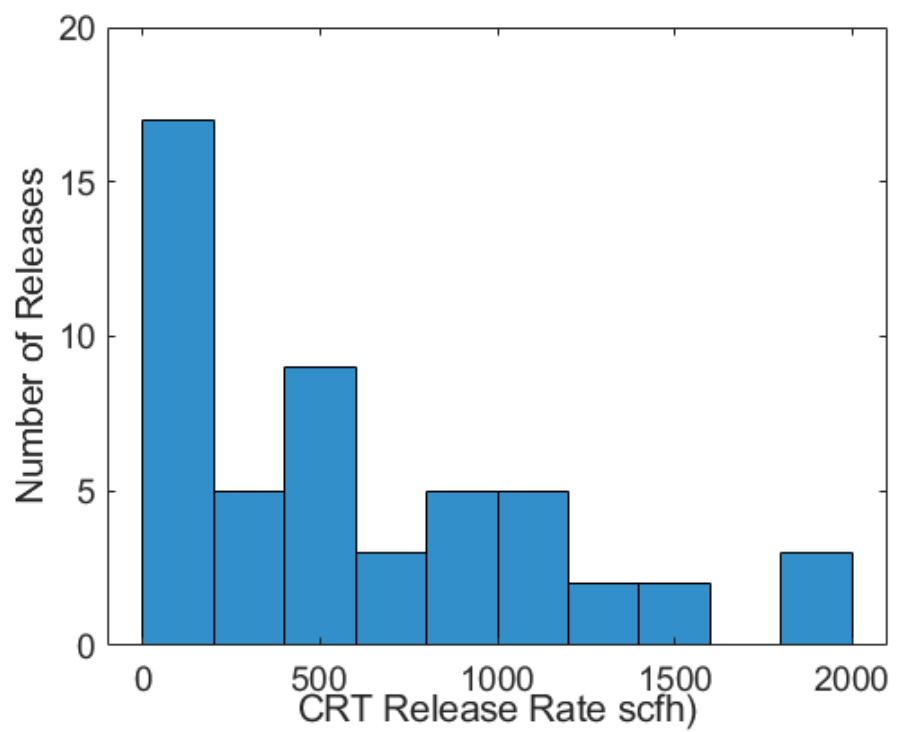

Figure S8: Histogram of the emission rates use in the controlled release tests in the AMFC phase 2 campaign. The emission rates spanned 3 orders of magnitude from about 30 scfh to about 2000 scfh.

The distribution of controlled release rates was such that only $20 \%$ of all releases were greater than $1000 \mathrm{scfh}$. These release rates were further randomly assigned to two different release heights ( 5 feet and 15 feet) to simulate equipment at different heights at oil and gas facilities. It also allowed evaluation of the quantification accuracy of technologies under differing air flows around release points, atmospheric dispersion, and imaging background.

Each team participated in 3 to 5 controlled releases per day. Teams were asked to start measuring when the release rate was stable and had a maximum of 15 minutes for quantification per release. Multiple teams could measure a release simultaneously provided they did not interfere with each other (e.g., a ground team and an aerial team). The CRT was conducted in a single-blind manner, with only the researchers and personnel from NTOC aware of the release rates.

\section{S.4.1. Controlled release test of Quantitative Optical Gas Imaging instrument}

AMFC phase 2 included CRT of the baseline QOGI instrument used to quantify methane emissions rates. Over a two-week period, about 100 individual controlled releases were tested by both OGI field two crews. The correlation parity chart between QOGI and the controlled releases is provided in the main text (Figure 1). Here, we conduct additional uncertainty analyzes, and describe the impact of release height and thermographer operation.

Effect of Release Height: Figure S5 shows CRT results for QOGI separated by stack height (5 ft and $15 \mathrm{ft}$ ), the line of best fit and the $95 \%$ confidence intervals. On average, QOGI underestimated emissions by $18 \%$ (overall regression slope of 0.82 ). Both OGI teams performed 
194

significantly better at detecting higher emissions from 15 feet with a regression slope of 0.92 where the $95 \%$ confidence interval is indistinguishable from the reference line of slope 1 , indicating no statistically significant difference from controlled release rate. Alternately, emissions at 5 feet exhibit an underestimation with regression slope of 0.67. One possible reason for this difference in quantification effectiveness between the two release heights has to do with the properties of the OGI camera. Prior research on camera performance has shown that a methane plume is better visible under imaging conditions that provide a larger apparent temperature contrast [41]. Tests from the $15 \mathrm{ft}$ release height were imaged using the sky as the background that typically have a lower apparent background temperature compared to ambient, thus resulting in better contrast. However, typical surveys at oil and gas sites encounter significantly more complex background environments and thus these results cannot be directly extrapolated. We recommend more controlled release testing around realistic equipment and site settings such as the METEC facility in Colorado to better understanding the accuracy and precision of the QOGI instrument.

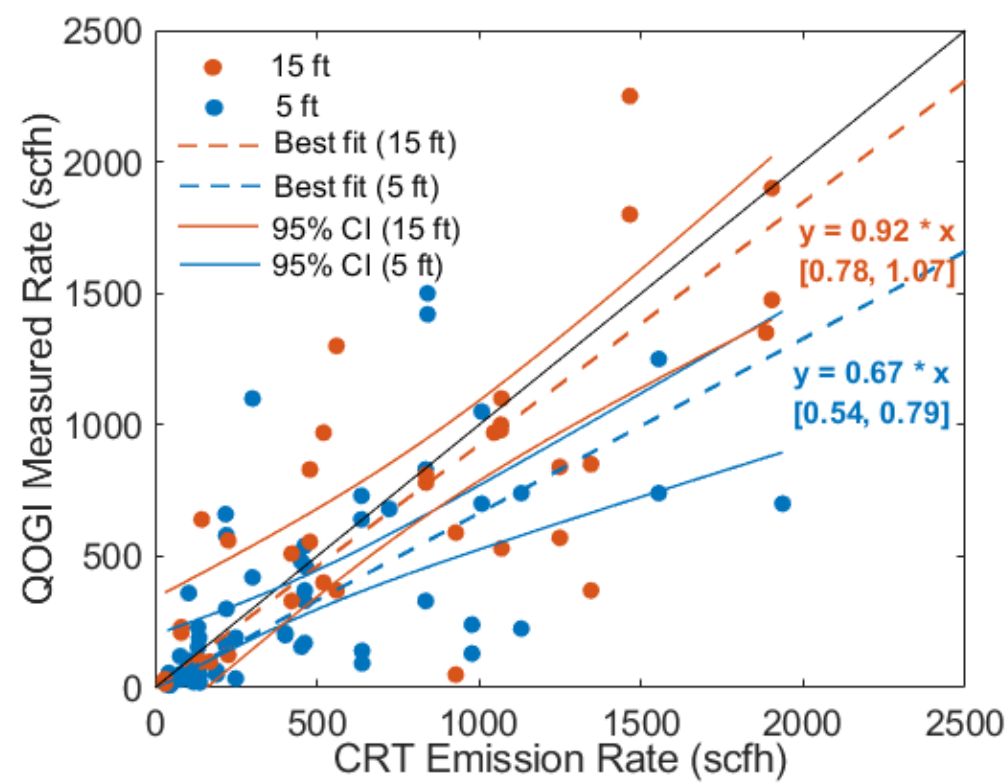

Figure S9: Parity chart showing CRT results for QOGI for the two release heights - $5 \mathrm{ft}$ (blue) and $15 \mathrm{ft}$ (orange), the line of best fit (dashed) and the 95\% confidence intervals. Reference line (black) has slope $=1$.

Effect of Thermographer Operation: Figure S6 shows the CRT results for the two OGI field teams. We find that, on average, there are differences between the two field teams where team 1 demonstrated a parity chart regression slope of 0.89 compared to team 2 with a regression slope of 0.76 . However, the overlap in the $95 \%$ confidence intervals of the two crews indicate that this difference might not be statically different. Even so, recent studies with several OGI camera operators conducted at the METEC test site in Colorado have demonstrated that operator experience plays a role in the effectiveness of leak detection [57]. We note that the two teams did not measure CRT simultaneously and thus the difference might also be attributable to differences in atmospheric conditions. 
221

222

223

224

225

226

227

228

229

230

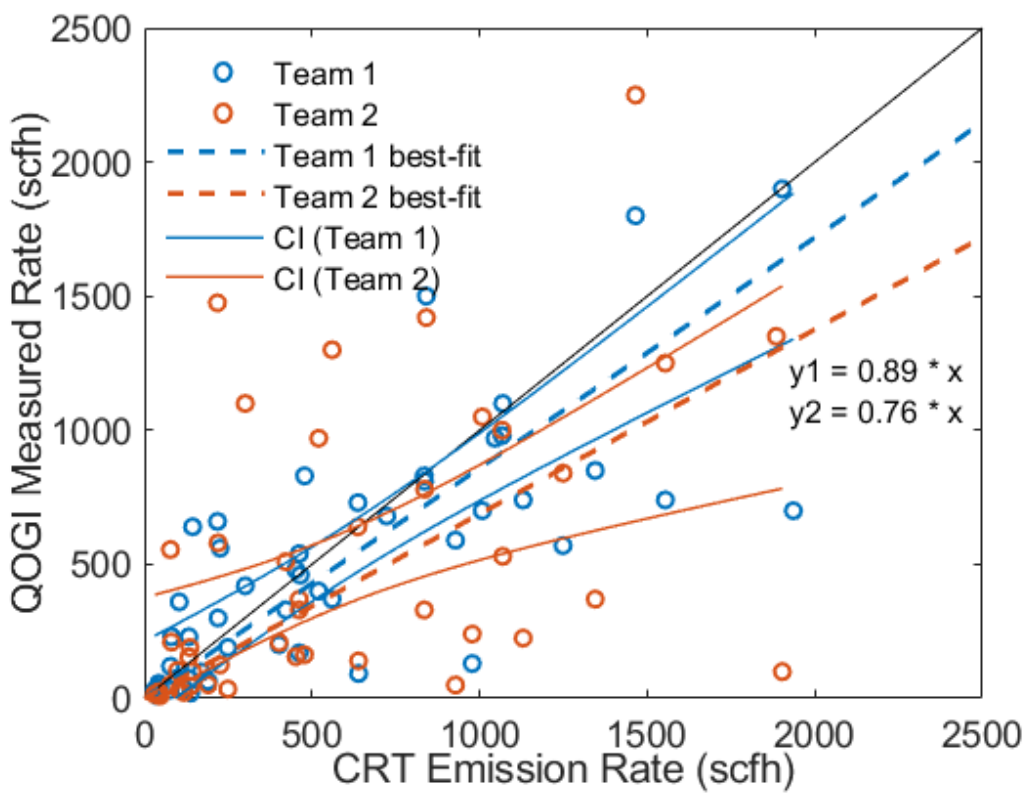

Figure S10: Parity chart of CRT emission rate and QOGI measured emission rate as a function of the two field crews that were deployed as part of the baseline OGI team in AMFC phase 2.

Uncertainty analysis: Figure S7 shows the histrograms of individual QOGI emissions estimate errors as a percentage of the true emission rates. The errors in individual quantification estimates are significantly larger than the aggregate error in emissions: the average error is an underestimation of $18 \%$ (range $-90 \%$ to $+330 \%$ ), with most errors falling within $\pm 50 \%$ range. Aggregate emissions estimate reduce uncertainty and are closer to actual emissions while individual measurements have high uncertainty and should not be used for comparing technology team performance. 


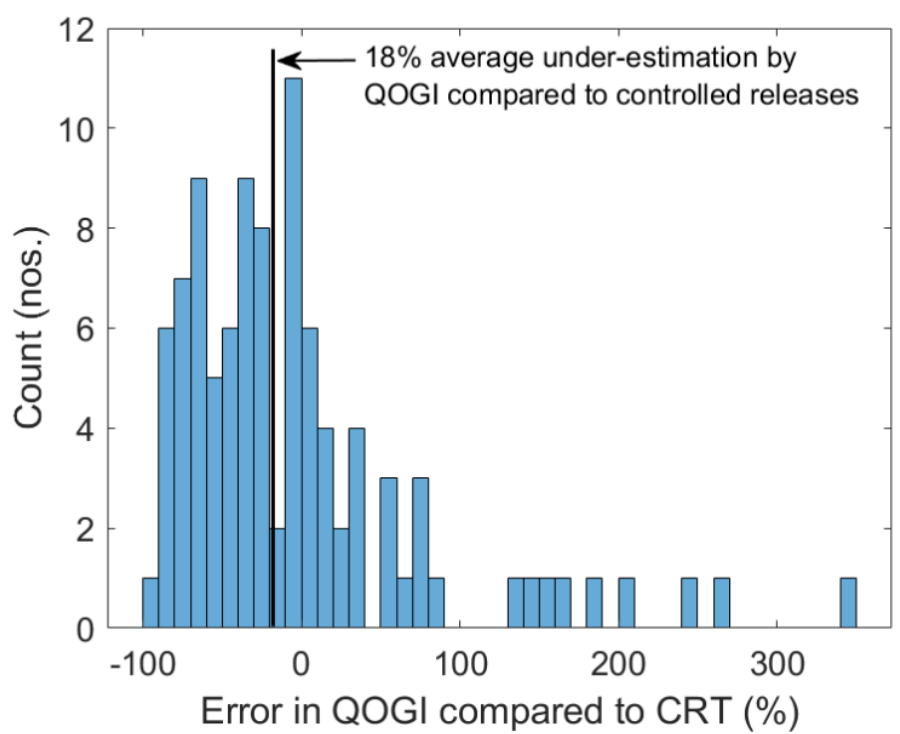

Figure S11: Histogram showing the relative error (\%) of QOGI emissions estimate compared to true value of controlled releases.

Monte-Carlo analysis: To further explore the uncertainty, we use bootstrapped Monte Carlo sizes. At each iteration, the average emission of the sample is calculated, as well as the 5-95 and 25-75 percentile thresholds as shown in Figure S8.

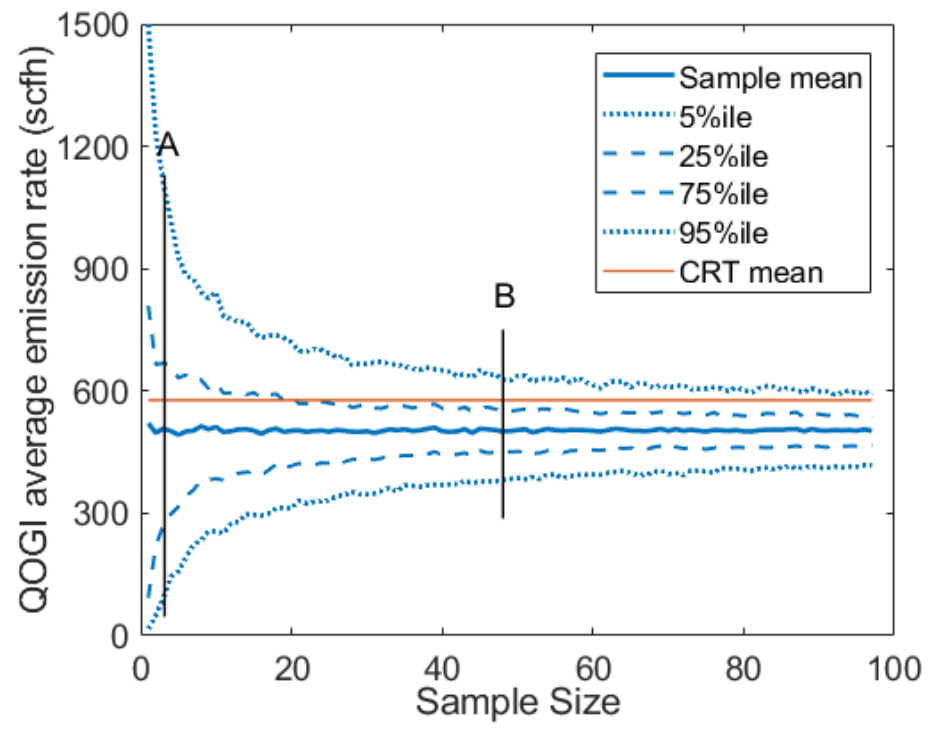

Figure S12: The errors in individual quantification estimates are significantly larger than the aggregate error in emissions.

242 For large sample sizes, the QOGI estimated sample mean is approximately $18 \%$ lower than the true sample mean, corresponding to the regression slope of 0.82 . More important, the uncertainty range around sample mean reduce rapidly as sample size increases. For example, measurement A 
with a sample size of 5 has a 5-95 percentile uncertainty of $[-75 \%,+85 \%]$ while measurement B with a sample size of 50 shows a corresponding uncertainty of $[-23 \%,+26 \%]$. Thus, it is critical to interpret QOGI measurements in aggregate as error in individual measurements can be significantly higher. Consequently, sites with fewer emissions will have larger aggregate error associated with them compared to those with more emissions.

\section{S.4.2. Controlled release test results from participating teams}

Figure S9 shows the quantification accuracy parity charts between controlled release rates and estimated rates by the participating teams. Only teams that quantified emissions rates during the controlled release testing are included in this analysis.

Truck-based teams: Altus underestimated overall emissions on average by $80 \%$ (combined slope $=0.2, \mathrm{R}^{2}=0.05$ ). However, we observed a significant difference across the two emission heights - at the $5 \mathrm{ft}$ release height, Altus underestimated emissions by $59 \%\left(\right.$ slope $\left.=0.41, \mathrm{R}^{2}=0.09\right)$ while at the $15 \mathrm{ft}$ release height, Altus underestimated by $95 \%$ (slope $=0.05, \mathrm{R}^{2}=0.57$ ). For releases lower than $300 \mathrm{scfh}$, the overall performance improved slightly for an underestimation by $72 \%$ (slope $=0.28$ ). UofC overestimated emissions by $35 \%$ (combined slope $=1.35, \mathrm{R}^{2}=$ 0.51 ) across both release heights. For releases at $5 \mathrm{ft}$, the UofC team demonstrated an average overestimation of about $64 \%$ (slope $=1.64, \mathrm{R}^{2}=0.56$ ), which reduced to $17 \%$ (slope $=1.17, \mathrm{R}^{2}$ $=0.48$ ) for releases from $15 \mathrm{ft}$.

Emissions quantification is a challenging problem influenced by several factors such as atmospheric conditions, data processing algorithms, instrument sensitivity, survey method, and gas composition. Therefore, it is not possible to attribute observed differences in these limited controlled release tests to any specific influencing factor. However, we note that in both the truck-based teams, the slope of regression moved in a direction that would indicate underestimation of emissions at $15 \mathrm{ft}$ compared to $5 \mathrm{ft}$. In the case of Altus Geomatics, the slope of regression reduced from 0.41 for releases at $5 \mathrm{ft}$ to 0.05 for releases at $15 \mathrm{ft}$. In the case of the University of Calgary, the slope of emissions reduced from 1.64 for releases at $5 \mathrm{ft}$ to 1.17 for releases at $15 \mathrm{ft}$. While variability in several factors that influence quantification estimates prevent us from drawing strong conclusions, it would be instructive to further explore the performance of truck-based systems from emissions from different heights.

Hand-held team: All CRT releases for Tecvalco were conducted at $5 \mathrm{ft}$ because of the need to attach a flowmeter directly to the emitting source. The $95 \%$ confidence intervals for Tecvalco include the reference 1:1 line showing that there is no statistically significant difference in its estimate of the true release rate. This high accuracy (regression slope $=1.05$ ) is expected given that the flow meter directly measures flow rate and does not rely on dispersion modeling and is not affected by environmental conditions. However, the requirement to attach the flowmeter to emitting sources for quantification limits the range of emissions that can be quantified by the team. In this scenario, this technology is similar to that of a conventional Bacharach Hi-Flow Sampler whose measurements are limited by access and safety considerations.

Plane-based team: Sander was only able to quantify emissions from 2 out of the 23 individual controlled release tests. Even though the team was able to correctly detect emissions during each survey, it was unable to quantify most of the releases due to unstable wind conditions or equipment issues. The two quantified emissions were estimated to be $90 \mathrm{scfh}$ and $418 \mathrm{scfh}$, compared to controlled release emission rates of $226 \mathrm{scfh}$ and $451 \mathrm{scfh}$, respectively. 


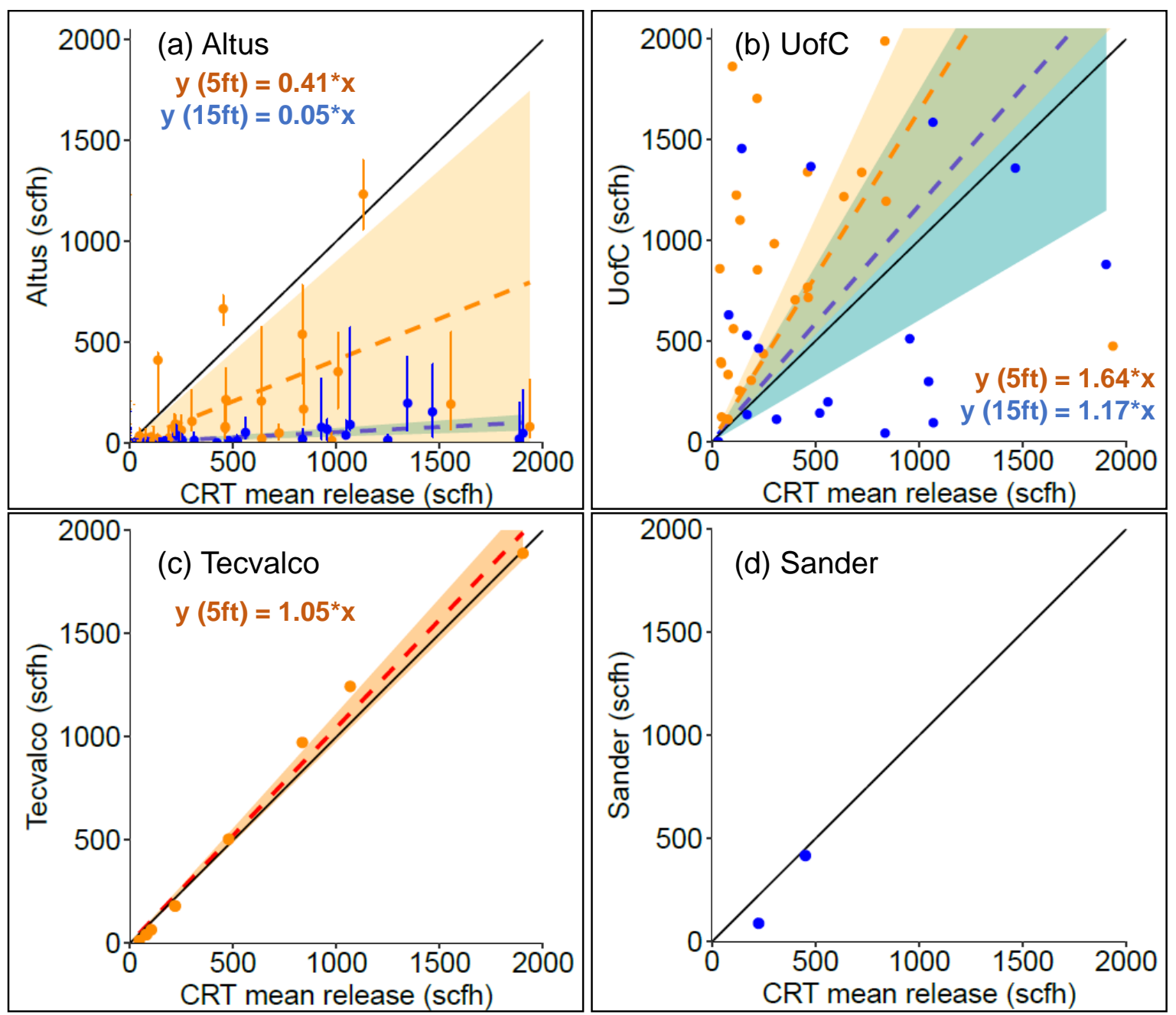

Figure S13: CRT parity charts showing the quantification by teams on the y-axis and the controlled release rates on the $x$-axis. The black line is the 1:1 reference line with slope $=1$. The plots are split by the two stack release heights of $5 \mathrm{ft}$ (Orange) and $15 \mathrm{ft}$ (blur). Tecvalco only measured at 5 feet and Sander quantified only 2 releases at 15 feet.

\section{S.5 Flow rate quantification}

Figure S10 shows the flow rate quantification accuracy at the site-level as a parity chart of OGI site-level emissions estimate and the estimates from participating teams for overlap sites. Discussion of the results of Figure S10 have also been included in the main text where relevant. If the quantification measurements between OGI and the participating team were identical, the data would plot on the black 1:1 reference line with a linear regression slope of 1 . When data are not on the reference line, the team either underestimated or overestimated emissions compared to OGI estimates, depending on the slope of the regression line. Regression slopes and confidence intervals are not shown for Bridger, Sander, and Tecvalco due to the limited number of data points. The error bars for teams are self-reported while error bars for OGI are based on 1 standard error from controlled release testing $(\sim 38 \mathrm{scfh})$.

This parity chart does not represent true quantification comparison because ground truth emissions at oil and gas sites is unknown. This only represents a comparison to an OGI-based 
306

307

308

309

310

311

survey where emissions were quantified using the QOGI instrument. In addition, all teams did not measure concurrently and therefore changes in atmospheric conditions or temporal variations in emissions can result in differences in quantification estimates that are independent of the technology or survey method. A true understanding of quantification accuracy should be tested using controlled release experiments as in the prior section and studies such as the mobile monitoring challenge Ravikumar et al., 2019 [21].

(a)

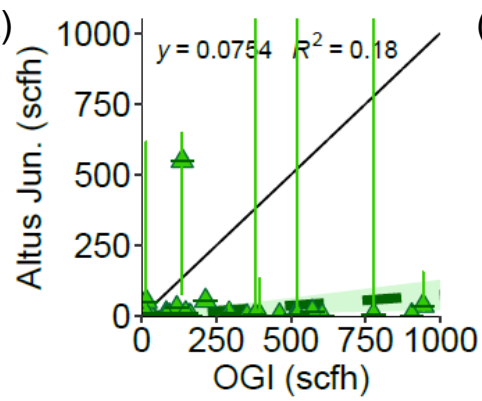

(d)

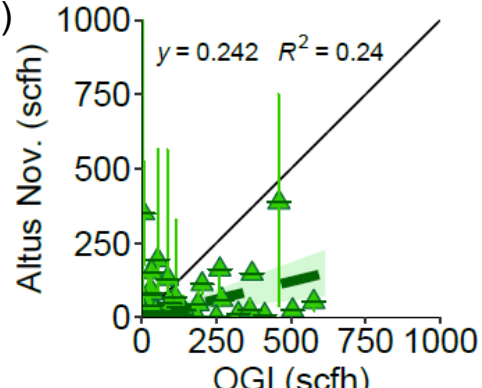

(g)

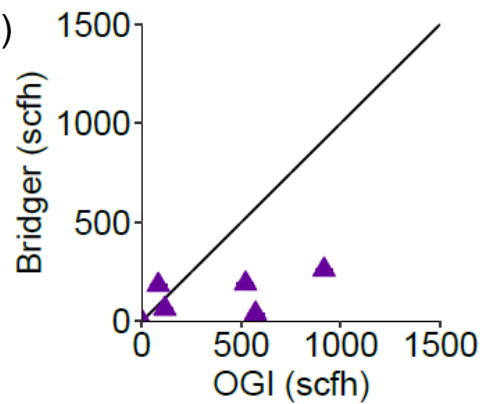

(b)

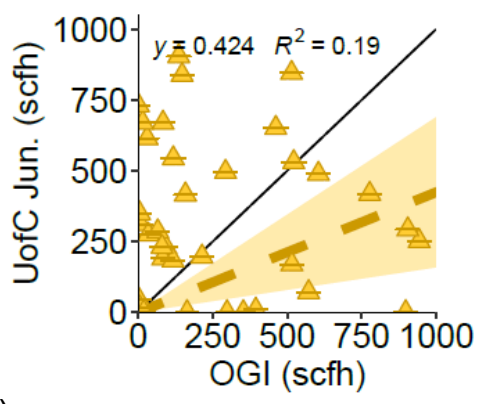

(e)

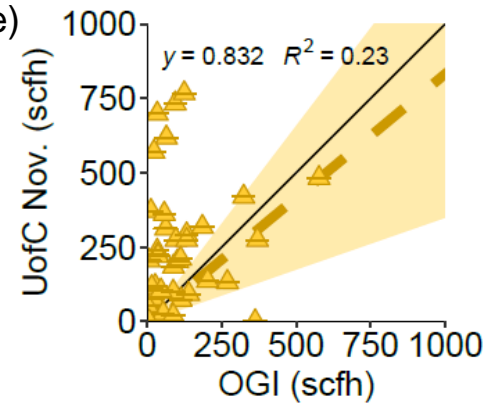

(h)

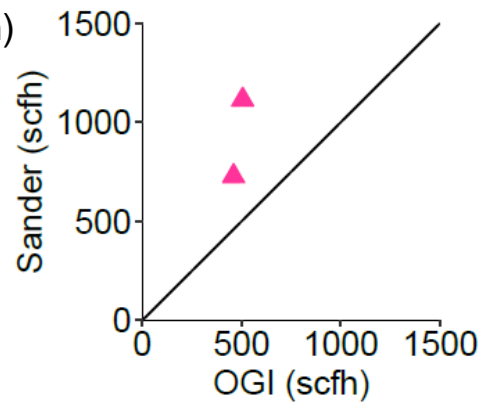

(c)

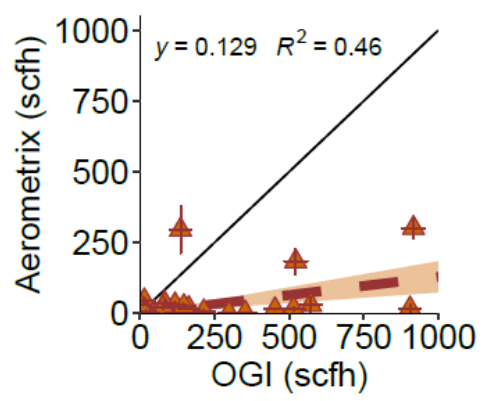

(f)

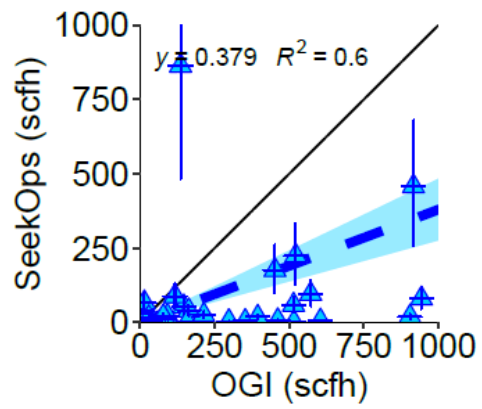

312

313

314

315

316

317

318

319

320

321

322

323

324

325

326

Figure S14: Parity plot showing flow rate quantification for the teams versus that of OGI aggregated at the site-level. OGI errors are based on 1 SE from CRT performance (38 scfh), and errors for respective teams, where applicable, are as reported by them. No regression line for Bridger, Sander and Tecvalco due to limited data points, and their scale is 0-1500scfh as compared to 0-1000scfh for all others. The black line is the 45degree 1:1 reference line. Liner regression slope is shown as the colored dotted lines while the shaded region is the $95 \%$ confidence band.

All teams significantly underestimated emissions by over $60 \%$ compared to QOGI-based estimates, except for the UofC team in phase 2. Altus underestimated emissions on average between $75 \%$ and $92 \%$, while UofC underestimated on average between $17 \%$ and $58 \%$. In addition, the nature of analysis presented here may also contribute to differences in emissions estimates. For example, while Altus collected site-level emissions data, the UofC team collected equipment-level data at each site. Aggregating equipment-level data to the site-level for comparison in this section may result in an underestimation if all emissions at the site were not detected by the UofC team because of intermittency in emissions or false negative detection. 
327 Tecvalco only measured component-level emissions that were accessible thus site-level

328 aggregation will necessarily be lower than that determined by OGI.

329 If we consider those sites where QOGI estimated emission estimates are less than $350 \mathrm{scfh}$,

330 quantification accuracy for most teams, as measured by the slope of regression, increases (Table

331 S2). According to QOGI estimates, 75\% of all site-level emissions were below 350 scfh across

332 both phases.

333 Table S5: Regression coefficients for all sites and for sites estimated at less than 350 scfh by QOGI.

\begin{tabular}{|l|r|r|}
\hline Technology Team & All sites & $\mathbf{7 5 \%}$ sites $<350$ scfh \\
\hline Aerometrix & 0.13 & 0.16 \\
\hline SeekOps & 0.38 & 0.42 \\
\hline Altus phase 1 & 0.08 & 0.17 \\
\hline Altus phase 2 & 0.24 & 0.26 \\
\hline UofC phase 1 & 0.42 & 2.02 \\
\hline UofC phase 2 & 0.83 & 2.05 \\
\hline
\end{tabular}

335 Linear regression to analyze quantification effectiveness is the standard practice in literature but 336 tends to weigh larger values more than smaller values. Thus, it can be challenging to evaluate 337 data from field experiments where emissions span several orders of magnitudes. Other methods 338 such as variance weighted least squares regression can be used in future work to analyze this 339 problem. 

ordered fraction of total sites. Here we compare site-level emissions-size distribution for all overlap sites covered by each team.
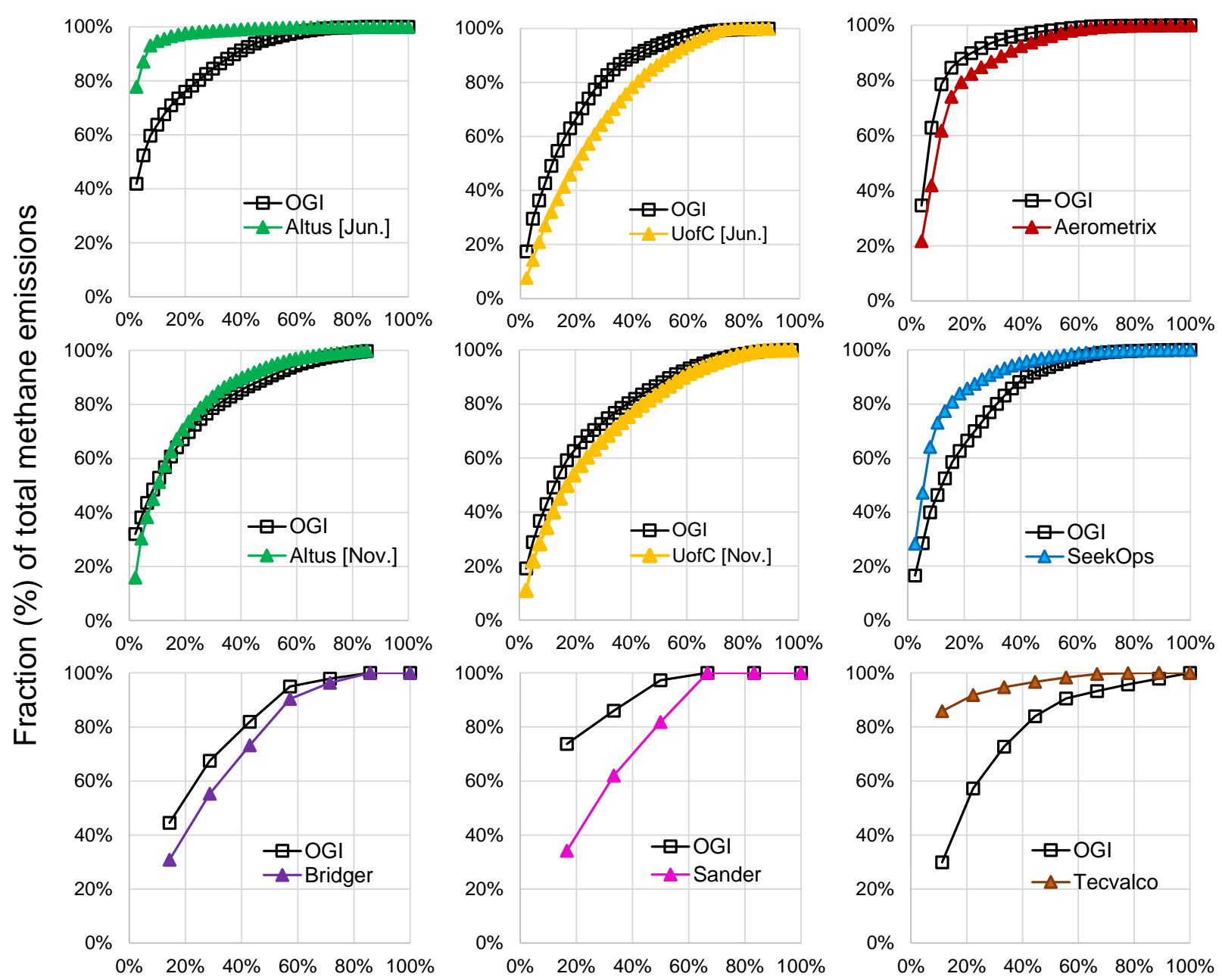

Fraction (\%) of total overlap sites

344

Figure S15: emissions size distribution for the various technology teams for overlap sites as a percentage of total sites ( $x$-axis) and total emissions ( $y$-axis).

Across all teams, top $20 \%$ of sites contributed between $40 \%$ and $90 \%$ of total emissions. For teams measuring at equipment-level, emissions were aggregated to the site level. Thus, any missing equipment-level emissions would not be aggregated resulting in a less skewed emissions distribution than those measured directly at site-level. 


\section{S.7 Limitations and recommendations}

In this section we discuss some of the challenges faced during AMFC field work and potential solutions that can be implemented in future field campaigns.

Temporal variation in methane emissions: Team performance in the AMFC cannot be taken as ground truth and 'missed' detections might not always be a failure of the team to detect given the intermittent nature of some emissions. OGI crews noted the nature of emissions, when possible, in their report. However, this does not provide any information on emission when other participating teams were on site. Further, intra-day variation in emissions from temperature or other factors are hard to account for. Future field campaigns should ensure that there are multiple redundant baseline measurement techniques deployed to better understand the true nature of emissions. The use of reliable continuous monitoring systems to identify intermittency would be critical to compare performance of technologies that undertake 'snapshot' measurements.

Operational limits: Technology teams have operational limits such as the ability to maneuver on site in a manner most suited for emissions detections and quantifications. For example, truck teams are sometimes unable to navigate downwind of all equipment on site which is important for quantification and detections, while drone- and plane-based teams might not be able to access equipment within buildings. While these are inherent to the characteristics of different platforms, it is an important consideration while comparing performance across teams and technologies.

\section{References}

[1] L. S. Rothman et al., "The HITRAN2012 molecular spectroscopic database," J. Quant. Spectrosc. Radiat. Transf., vol. 130, pp. 4-50, 2013.

[2] A. E. S. Green, R. P. Singhal, and R. Venkateswar, "Analytic extensions of the gaussian plume model," J. Air Pollut. Control Assoc., vol. 30, no. 7, pp. 773-776, 1980.

[3] F. Pasquill, "The Estimation of the Dispersion of Windborne Material.," Meteorol. Mag., vol. 90, pp. 33-49, 1961.

[4] F. A. Gifford, "Use of Routine Meteorological Observations for Estimating Atmospheric Dispersion,” Nucl. Saf., vol. 2, no. 4, pp. 47-51, 1961.

[5] Y. Y. Cui et al., "Top-down estimate of methane emissions in California using a mesoscale inverse modeling technique: The South Coast Air Basin," J. Geophys. Res. Atmos., vol. 120, no. 13, pp. 6698-6711, Jul. 2015.

[6] A. P. Ravikumar et al., "Single-blind inter-comparison of methane detection technologies - results from the Stanford/EDF Mobile Monitoring Challenge," Elem Sci Anth, vol. 7, no. 1, p. 37, Sep. 2019.

[7] A. P. Ravikumar, J. Wang, and A. R. Brandt, "Are Optical Gas Imaging Technologies Effective for Methane Leak Detection?,” Environ. Sci. Technol., vol. 51, no. 1, pp. 718-724, 2017.

[8] D. Zimmerle, T. Vaughn, C. Bell, K. Bennett, P. Deshmukh, and E. Thoma, "Detection Limits of Optical Gas Imaging for Natural Gas Leak Detection in Realistic Controlled Conditions," Environ. Sci. Technol., vol. 54, no. 18, pp. 11506-11514, Sep. 2020. 